\title{
ANÁLISIS DE LAS ELECCIONES MUNICIPALES Y AUTONÓMICAS DE 28 DE MAYO DE 1995
}

\author{
AURORA GUTIÉRREZ NOGUEROLES \\ Profesora Asociada de Derecho Constitucional \\ UNED
}




\section{SUMARIO}

I. INTROdUCCIÓN. II. La campaña electoral III. Las elecciones municipales. III.1. Participación. III.2. Resultados electorales. III.3. Análisis de los resultados electorales. IV. LAS eleCCIONES aUtONómiCAS. IV.1. Participación. IV.2. Resultados electorales. IV.3. Análisis de los resultados electorales. IV.4. Consecuencias políticas post-electorales. V. LAS ELECCIONES EN CEUTA Y MeLILLA. 


\title{
ANÁLISIS DE LAS ELECCIONES MUNICIPALES Y AUTONÓMICAS DE 28 DE MAYO DE 1995
}

\author{
POR

\section{AURORA GUTIÉRREZ NOGUEROLES} \\ Profesora Asociada de Derecho Constitucional
}

UNED

\section{INTRODUCCIÓN}

Dando cumplimiento a lo dispuesto en el artículo 42.3 de la Ley Orgánica 5/1985, de 19 de junio, del Régimen Electoral General, se convocaban por Real Decreto 489/1995, de 3 de abril (BOE no 80/1995, de 4 de abril) elecciones locales en todo el territorio español ${ }^{1}$, mediante las que se renovarían los distintos cargos públicos del ámbito municipal: concejales (en municipios de cien o más habitantes sin régimen de Concejo Abierto), alcaldes (en municipios de menos de cien habitantes y en los de régimen de Concejo Abierto), alcaldes pedáneos $u$ órgano unipersonal equivalente (en las entidadeś territoriales de rango inferior al municipio) y consejeros (en los cabildos insulares del Archipiélago Canario).

Igualmente y mediante el mismo Decreto, se convocaban por vez primera elecciones para la constitución de las Asambleas de Ceuta y Melilla,

Sólo para aquellas circunscripciones donde, tras estas elecciones, todos o algunos de los puestos a cubrir resultaran vacantes, bien por ausencia de candidatos, bien por haberse declarado la nulidad total o parcial de la elección efectuada, se convocarian posteriormente elecciones locales parciales, mediante Real Decreto 1495/1995, de 11 de septiembre (BOE n. $.218 / 1995$ ). La fecha de celebración de éstas se fijó para el domingo 5 de noviembre de 1995. 
cuyos Estatutos de Autonomía, recientemente aprobados ${ }^{2}$, disponen la coincidencia de sus respectivas elecciones asamblearias con las elecciones locales. La fecha de éstas es —como se sabe - la única en el calendario electoral español que tiene un cierto carácter de fijeza, ya que deben celebrarse - a tenor de lo dispuesto en el citado artículo 42.3 LOREG- cada cuatro años, en el cuarto domingo del mes de mayo. De esta forma, la fecha de celebración de estas últimas elecciones locales correspondía al domingo 28 de mayo de 1995.

Con referencia a esta misma fecha y porque así lo disponen sus respectivos Estatutos de Autonomía, se convocaron asimismo, mediante los correspondientes Decretos ${ }^{3}$ autonómicos, elecciones a las Asambleas legislativas de trece Comunidades Autónomas (esto es, de todas menos Andalucía, Cataluña, Galicia y País Vasco).

En todas las citadas disposiciones normativas de convocatoria hubo, lógicamente, coincidencia en fijar la duración de la campaña electoral, que debía ser de quince días, comenzando a las cero horas del viernes 12 de mayo de 1995 y finalizando a las veinticuatro horas del viernes 26 del mismo mes. La víspera de la fecha electoral tenía, como es normal, carácter de «día de reflexión».

\section{LA CAMPAÑA ELECTORAL}

Al haber dejado de ser parte relevante de la confrontación política el Centro Democrático y Social, sólo entraban realmente en liza, al iniciarse

2 Por Ley Orgánica núm. 1/1995, de 13 de marzo, para Ceuta; y por Ley Orgánica núm. 2/1995, de 13 de marzo, para Melilla.

3 En detalle, son los siguientes Decretos: núm. 3/1995, del Presidente del Principado de Asturias; núm. 1 0/1995, del Presidente de Cantabria; núm. 2/1995, del Presidente de La Rioja; núm. 5/1995, de la Presidenta de la Región de Murcia; núm. 7/1995, del Presidente de la Generalidad Valenciana; sin número, de la Presidencia de la Diputación General de Aragón; núm. 28/1995, del Presidente del Gobierno de Castilla-La Mancha; núm. 68/1995, del Presidente de la Comunidad Autónoma de Canarias; núm. 5/1995, del Presidente del Gobierno de Navarra; núm. 12/1995, del Presidente de la Junta de Extremadura; núm. 31/1995, del Presidente de la Comunidad Autónoma de las Islas Baleares; núm. 30/1995, del Presidente de la Comunidad Autónoma de Madrid; y núm. 59/1995, del Presidente de la Junta de Castilla y León. Todos los Decretos relacionados llevan fecha de 3 de abril y han sido publicados, además de en los Boletines Oficiales de sus respectivas Comunidades Autónomas, en el Boletín Oficial del Estado núm. 80/1995, de 4 de abril (págs. 10.094-10.101). 
la campaña electoral, las tres únicas fuerzas "estatales" consideradas como significativas (esto es, el Partido Popular, el Partido Socialista Obrero Español y la coalición Izquierda Unida), que eran las que, en principio, estaban llamadas a repartirse la mayoría de los escaños en disputa, haciendo, claro es, la salvedad de algunas circunscripciones, tanto autonómicas como municipales, donde determinados partidos de corte nacionalista 0 regionalista 0 determinadas candidaturas independientes del ámbito local también aspiraban, con más o menos garantías, a entrar en el reparto.

En líneas generales, la campaña electoral se caracterizó por una gran dosis de vehemencia y agresividad verbal, así como por la ausencia de debate sobre los grandes temas de fondo. En los mítines pudo observarse una acentuada tendencia a la «americanización», primando la televisión sobre los demás medios de comunicación de masas. Los despliegues técnicos fueron, en efecto, impresionantes (megafonía, luminotecnia, escenarios móviles, efectos especiales, etc.) y todos ellos dirigidos a ser captados, en algún momento, por las cámaras de televisión, pues eran los televidentes quienes, en último término, debían ser los destinatarios del mensaje electoral. La radio y la prensa escrita fueron, por el contrario, casi ignoradas ${ }^{4}$.

La estrategia electoral del PP se encaminó fundamentalmente a convencer a los votantes del carácter "primario" de estas elecciones, a su consideración como una "antesala" de las próximas generales, las cuales - según apreciación mayoritaria- pensaban exigir inmediatamente en caso de producirse el descenso de votos socialistas que pronosticaban las encuestas. Coincidian en la atribución de tal carácter destacados analistas políticos de distinto signo. Así, para J. TUSELL, "[...] la campaña ha tenido una dimensión de política nacional. Es obvio que [...] lo que parece en cuestión no es tanto unos alcaldes o unos presidentes como los límites de una ola política de fondo en la sociedad" 5 ; $y$, según A. ELORZA, "el hecho de [considerar] estas elecciones como primarias se deriva de una conciencia generalizada: existe gran distancia entre lo que representa el Gobierno y las opciones políticas dominantes en la sociedad española» ${ }^{6}$. Independientemente de la dosis cierta de subjetivismo que

4 En este sentido, M. A. AGUILAR en Cambio $16 \mathrm{n} .^{\circ} 1228$, Suplemento Especial, de 5 de junio de 1995, pág. 12.

5 TUSELL, J.: Un final de época, en Cambio 16 cit., pág. 10.

6 Elorza, A.: La voluntad de durar, en Cambio 16 cit., pág. 14. 
encierran estos análisis, no puede desconocerse que la vinculación entre una política nacional salpicada por diversos escándalos de corrupción y la futura política municipal y autonómica que nacería de las urnas no era, desde luego, un argumento rechazable a priori por los responsables de la estrategia popular. Como subrayaba R. OROZCO, para los electores "era, sin duda, muy dificil separar el nombre del alcalde de su pueblo o del presidente de su Comunidad de los Rubio, Roldanes, Filesas y otros [...] " ${ }^{7}$ y de ello pretendían aprovecharse los estrategas del Partido Popular, cuyo discurso básico venía a centrarse en la urgente necesidad de cambio en las instituciones que, tanto a nivel central como autonómico y municipal, demandaba la sociedad española. Ahora bien, como ha puesto de relieve el politólogo J.I. WERT ${ }^{8}$, esta estrategia de "primarizar" en exceso las elecciones tenía el riesgo de incentivar a última hora a los llamados "votantes de baja intensidad" del PSOE, que podian finalmente - como ya ocurriera en las elecciones generales de 1993 - inclinar la balanza a favor de este partido. De ahí que tanto para prevenir dicho riesgo, como para ofrecer una imagen más adecuada a su carácter de "fuerza de gobierno" " ${ }^{9}$ en la campaña protagonizada por los populares ( $y$ centrada, particularmente, en la incesante actividad de su líder nacional, José María Aznar) se rehuyera, en la medida de lo posible, el debate sobre los grandes temas conflictivos que habían sacudido la vida política del país en los meses previos a la confrontación electoral. Sólo las circunstancias obligaron en una ocasión a los populares al enfrentamiento abierto con los socialistas y fue cuando éstos sacaron "oportunamente" a la luz el tema de la supresión de desgravaciones fiscales que incluía el programa de gobierno del PP. Y cierto es que algunas declaraciones contradictorias sobre dicho tema por parte de diversos dirigentes populares debilitaron, en alguna medida, la posición del partido ante los electores.

Pero no debían ir muy descaminados los estrategas del PP en su advertencia sobre el aludido riesgo de movilización electoral de última hora cuando sus más directos adversarios - los responsables de la campaña socialista - propugnaron un cambio de ésta, en el sentido de dirigirla primordialmente a potenciar la participación del electorado «pasivo»

7 R. Orozco en Cambio 16 cit., pág. 3.

- WERT, J.I.: Poder, tiempo y espacio: las elecciones municipales y autonómicas del 28-M, en la revista Claves de Razón Práctica, núm. 54 (julio-agosto, 1995), pág. 25.

9 En este sentido, PALLARÉs, F. y Soler, J.: Las elecciones autonómicas de mayo de 1995: una perspectiva general, pág. 547. 
socialista. En la campaña socialista pueden distinguirse, en efecto, dos diferentes fases: en la primera de ellas, el eje principal de la campaña consistió en desvirtuar ese carácter de "primarias» que los populares adjudicaban a las elecciones, haciendo hincapié en la desvinculación existente entre unos comicios de ámbito autonómico y municipal y los que tienen una dimensión nacional, y advirtiendo, con vistas a lo que pudiera ocurrir, que los resultados de aquéllos no tenían por qué influir en la gobernación del Estado, determinada exclusivamente por el resultado de las elecciones generales; en una segunda fase, sin embargo, y quizás motivado por unos pronósticos no demasiado halagüeños, se percibe una cierta aproximación al enfoque dado por la estrategia popular, propugnándose una «lectura política general del proceso electoral» ${ }^{10}$, cuya clave se sitúa en el slogan de la campaña ("Precisamente ahora") y que debía conducir a una movilización de todo el potencial electorado socialista en orden a evitar el riesgo cierto de un desplome del PSOE ante la avalancha electoral de los populares. En esta segunda fase de la campaña destacados dirigentes socialistas plantean «un discurso fundamentalmente estatal» "11, defendiendo la acción del gobierno socialista, llamando al "voto útil» y utilizando argumentos de corte "catastrofista», dirigidos a descalificar apriorísticamente la política de derechas a que conduciría una hipotética victoria del PP. Podría decirse que, al menos en parte, este giro estratégico consiguió el efecto deseado, pues propició una altísima participación en relación con la que suele ser habitual en este tipo de comicios, lo que contribuyó, sin duda, a suavizar los términos de la derrota socialista.

Por su parte, el discurso electoral de la tercera gran fuerza "estatal» -la coalición Izquierda Unida- se basó en la peculiar «teoría de las dos orillas", defendida por su líder nacional Julio Anguita. Para éste, en efecto, tanto el PP como el PSOE se hallaban situados en la "orilla derecha», siendo en exclusiva su coalición la que, situándose en solitario en la "orilla izquierda", podía defender los intereses de la clase trabajadora y, en general, los valores del progresismo político. La campaña de IU se dirigió, pues, a buscar el voto del electorado de izquierdas, mediante un discurso de ciertas connotaciones "didácticas", que a veces rayó en la agresividad (se llegó, por ejemplo, a culpar a los trabajadores de buscarse su propia «desgracia» por votar socialista). Con ello se pretendía 
conseguir nada menos que un histórico sorpasso ${ }^{12}$ del PSOE por parte de IU, que se convertiría así en el partido hegemónico de la izquierda.

Éstas fueron, pues, en general, las líneas estratégicas de las tres grandes fuerzas electorales del Estado que sirvieron para encauzar las respectivas campañas. Su éxito o fracaso sólo puede ser calibrado - como parece evidente- por referencia a los resultados obtenidos en la confrontación electoral.

\section{LAS ELECCIONES MUNICIPALES}

\section{III.1. Participación}

La coincidencia estratégica de populares y socialistas en atribuir el carácter de "primarias" a estas elecciones tuvo su indudable reflejo en la alta participación ciudadana que se ha registrado en ellas. Se trata, en efecto, de la elección municipal donde ha habido un mayor número de votantes: de los 32.021 .812 votantes potenciales que configuraban el censo electoral, nada menos que 22.327.530 ejercieron su derecho al voto, lo que representa un porcentaje del 69,72 . Para dar una idea de lo que significa tal porcentaje, obsérvese que la media de participación en los catorce procesos electorales o refrendarios habidos entre 1976 y 1991, según ha sido calculado por J.M. ASTORKIA ${ }^{13}$, se sitúa en el $68,3 \%$. Y de los cinco procesos electorales de ámbito municipal celebrados hasta la fecha es, desde luego, el de mayor participación (véase Cuadro I), siendo el de junio de 1987, donde coincidieron elecciones locales, autonómicas de trece Comunidades y europeas, el que más se le aproxima (con una participación del $69,13 \%)$.

12 Con este término se designó en la Italia de los setenta y ochenta a la hipótesis, nunca llevada a efecto en la práctica, de que el eurocomunista $\mathrm{PCl}$ sobrepasara a la Democracia Cristiana en la confrontación electoral.

13 AstoRKIA, J.M.: Evolución de la abstención electoral en España, en "Comportamiento político y electoral” (comp. Pilar del Castillo), Centro de Investigaciones Sociológicas, Madrid, 1994. 


\section{CUADRO !}

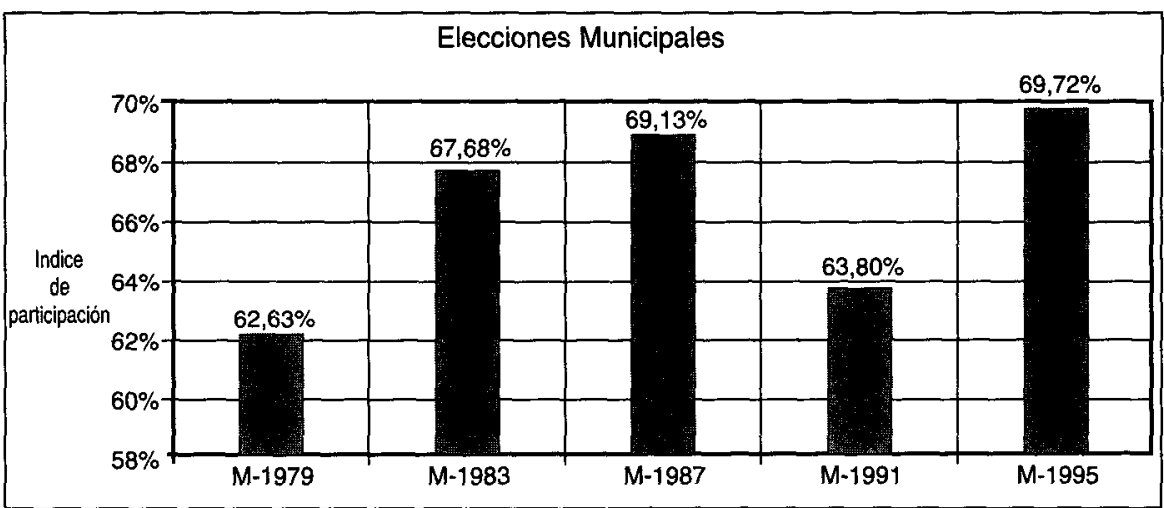

En comparación con las últimas elecciones municipales celebradas, las de 1991, el porcentaje de participación ha subido en casi seis puntos, constituyendo las localidades de más de 50.000 habitantes el principal causante de tal aumento, toda vez que en dicho estrato poblacional la diferencia de participación entre una y otra elección se sitúa en casi diez puntos porcentuales (véase Cuadro II).

\section{CUADRO II}

Distribución de la participación por estratos de población

\begin{tabular}{lll}
\hline & $M-1991$ & M-1995 \\
\hline Núcleos urbanos de hasta 250 habitantes & $75,12 \%$ & $80,53 \%$ \\
Núcleos urbanos entre 251 y 5.000 habitantes & $76,17 \%$ & $79,09 \%$ \\
Núcleos urbanos entre 5.001 y 20.000 habitantes & $68,97 \%$ & $72,33 \%$ \\
Núcleos urbanos entre 20.001 y 50.000 habitantes & $62,11 \%$ & $68,51 \%$ \\
Núcleos urbanos de más de 50.001 habitantes & $56,37 \%$ & $66,11 \%$ \\
\hline MEDIA TOTAL ........................63,80\% & $69,72 \%$ \\
\hline
\end{tabular}

Fuente: Ministerio de Justicia e Interior. Colección Documentos Electorales n.ำ 5: Elecciones Locales 1995.

\section{III.2. Resultados electorales}

De acuerdo con los datos publicados por la Junta Electoral Central en el BOE n. ${ }^{-173}$ de 21 de julio de 1995, los resultados electorales en las distintas capitales de provincia han sido los siguientes: 


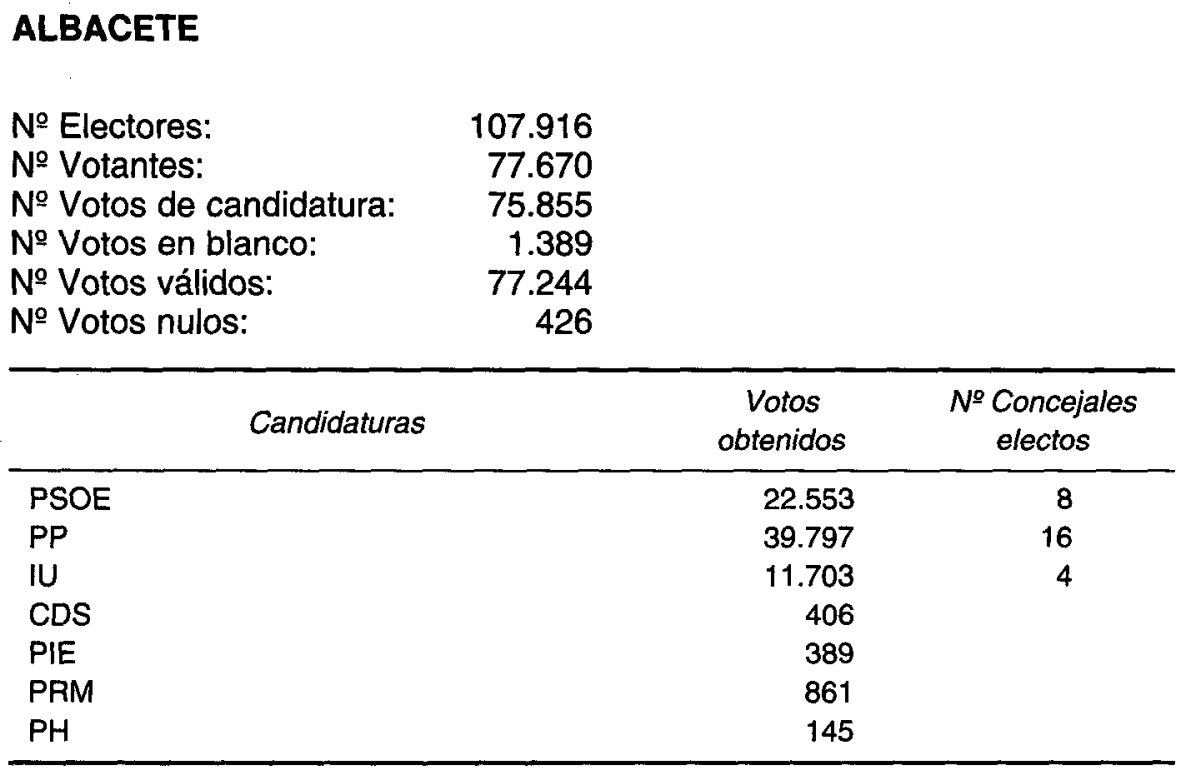

\section{ALICANTE}

\begin{tabular}{|c|c|c|c|}
\hline $\begin{array}{l}\text { № Electores: } \\
\text { № Votantes: } \\
\text { № Votos de candidatura: } \\
\text { № Votos en Blanco } \\
\text { № Votos válidos: } \\
\text { № Votos nulos: }\end{array}$ & $\begin{array}{r}214.354 \\
150.463 \\
147.937 \\
1.816 \\
149.753 \\
908\end{array}$ & & \\
\hline \multicolumn{2}{|c|}{ Candidaturas } & $\begin{array}{c}\text { Votos } \\
\text { obtenidos }\end{array}$ & $\begin{array}{c}\text { No Concejales } \\
\text { electos }\end{array}$ \\
\hline \multicolumn{2}{|l|}{ PP } & 72.004 & 14 \\
\hline \multicolumn{2}{|l|}{ PSOE } & 54.120 & 10 \\
\hline \multicolumn{2}{|l|}{ EU-EV } & 17.262 & 3 \\
\hline \multicolumn{2}{|l|}{ Bloque Progresista } & 134 & \\
\hline \multicolumn{2}{|c|}{ Esquerra Republicana de Catalunya } & 283 & \\
\hline \multicolumn{2}{|c|}{ Partido Solidaridad Cívica de Alicante } & 1.621 & \\
\hline \multicolumn{2}{|l|}{ FEJONS } & 182 & \\
\hline \multicolumn{2}{|l|}{ Unión Provincial Alicantina } & 173 & \\
\hline \multicolumn{2}{|l|}{ PC Pueblos de España } & 378 & \\
\hline \multicolumn{2}{|l|}{ Alicante Unida } & 1.192 & \\
\hline \multicolumn{2}{|c|}{ Unión Democrática Independiente } & 575 & \\
\hline
\end{tabular}




\section{ALMERIA}

№ Electores:

125.764

№ Votantes:

83.262

№ Votos de candidatura:

82.239

№ Votos en blanco

792

№ Votos válidos:

83.031

№ Votos nulos:

231

\begin{tabular}{lrc}
\hline Candidaturas & $\begin{array}{c}\text { Votos } \\
\text { obtenidos }\end{array}$ & $\begin{array}{c}\text { No Concejales } \\
\text { electos }\end{array}$ \\
\hline PP & 40.530 & 14 \\
PSOE & 25.725 & 9 \\
IUCA & 12.945 & 4 \\
PA & 1.161 & \\
NA & 796 & \\
PIE & 616 & \\
PAP & 466 & \\
\hline
\end{tabular}

\section{ÁVILA}

№ Electores: $\quad 37.682$

№ Votantes: $\quad 25.795$

№ Votos de candidatura: $\quad 25.056$

№ Votos en blanco $\quad 564$

№ Votos válidos: $\quad 25.620$

№ Votos nulos: $\quad 302$

\begin{tabular}{lcc}
\hline \multicolumn{1}{c}{ Candidaturas } & $\begin{array}{c}\text { Votos } \\
\text { obtenidos }\end{array}$ & $\begin{array}{c}N^{\circ} \text { Concejales } \\
\text { electos }\end{array}$ \\
\hline PSOE & 3.689 & 3 \\
PP & 16.344 & 14 \\
IU & 3.612 & 3 \\
Agrupación Independiente de Ávila & 1.411 & 1 \\
\hline
\end{tabular}




\section{BADAJOZ}

№ Electores:

98.072

№ Votantes:

70.872

№ Votos de candidatura:

69.663

№ Votos en blanco

855

№ Votos válidos:

70.518

№ Votos nulos:

354

\begin{tabular}{lrc}
\hline Candidaturas & $\begin{array}{c}\text { Votos } \\
\text { obtenidos }\end{array}$ & $\begin{array}{c}\text { No Concejales } \\
\text { electos }\end{array}$ \\
\hline PP & 37.751 & 16 \\
PSOE & 20.401 & 8 \\
IU & 9.426 & 3 \\
Coalición Extremeña & 1.999 & \\
Falange Española & 86 & \\
\hline
\end{tabular}

\section{BARCELONA}

№ Electores:

№ Votantes:

№ Votos de candidatura:

№ Votos en blanco

№ Votos válidos:

№ Votos nulos:
1.368 .148

906.038

895.760

8.263

904.023

2.015

\begin{tabular}{lrr}
\hline \multicolumn{1}{c}{ Candidaturas } & $\begin{array}{c}\text { Votos } \\
\text { obtenidos }\end{array}$ & $\begin{array}{c}\text { No Concejales } \\
\text { electos }\end{array}$ \\
\hline IC-EV & 68.813 & 3 \\
CIU & 276.276 & 13 \\
Federación Plataforma Independiente España & 320 & \\
OEstado Nacional Europeo & 181 & 0 \\
CDS & 1.256 & 0 \\
Plataforma Civica-Nuevo Partido Socialista & 571 & 0 \\
PSC-PSOE & 347.083 & 16 \\
Coalición Plataforma Humanista & 298 & 0 \\
Partit Obrer Revolucionari & 726 & 0 \\
PP & 150.284 & 7 \\
Partit Revolucionari Treballadors & 376 & 0 \\
ERC & 46.272 & 2 \\
Alternativa Ecologista Catalunya (Verds Europeu) & 3.304 & 0 \\
\hline
\end{tabular}




\section{BILBAO}

№ Electores:

313.693

№ Votantes:

191.778

№ Votos de candidatura: $\quad 187.977$

№ Votos en blanco:

2.688

№ Votos válidos:

190.665

№ Votos nulos:

1.113

\begin{tabular}{lrc}
\hline \multicolumn{1}{c}{ Candidaturas } & $\begin{array}{c}\text { Votos } \\
\text { obtenidos }\end{array}$ & $\begin{array}{c}\text { No Concejales } \\
\text { electos }\end{array}$ \\
\hline IU-EB & 14.031 & 2 \\
PSE-EE (PSOE) & 27.381 & 4 \\
EAJ-PNV & 50.598 & 9 \\
EA & 7.535 & \\
HB & 15.451 & 2 \\
Nuevo Partido Socialista (NPS) & 108 & 5 \\
Iniciativa Ciudadana Vasca (ICV-Gorordo) & 32.129 & 7 \\
PP & 40.457 & \\
PIE & 287 & \\
\hline
\end{tabular}

\section{BURGOS}

№ Electores:

133.493

№ Votantes:

90.549

№ Votos de candidatura: $\quad 87.434$

№ Votos en blanco:

2.285

№ Votos válidos:

89.719

№ Votos nulos:

830

\begin{tabular}{|c|c|c|}
\hline Candidaturas & $\begin{array}{c}\text { Votos } \\
\text { obtenidos }\end{array}$ & $\begin{array}{c}\text { № Concejales } \\
\text { electos }\end{array}$ \\
\hline TC-PNC & 1.933 & \\
\hline IU & 14.126 & 5 \\
\hline PUL & 5.523 & 1 \\
\hline PSOE & 15.680 & 5 \\
\hline SI & 3.131 & \\
\hline RB & 561 & \\
\hline UPB-CEC & 748 & \\
\hline$P P$ & 46.133 & 16 \\
\hline
\end{tabular}




\section{CÁCERES}

\begin{tabular}{|c|c|c|c|}
\hline № Electores: & 61.819 & & \\
\hline № Votantes: & 44.369 & & \\
\hline № Votos de candidatura: & 43.507 & & \\
\hline № Votos en blanco: & 628 & & \\
\hline N Votos válidos: & 44.135 & & \\
\hline № Votos nulos: & 237 & & \\
\hline \multicolumn{2}{|l|}{ Candidaturas } & $\begin{array}{c}\text { Votos } \\
\text { obtenidos }\end{array}$ & $\begin{array}{c}\text { № Concejales } \\
\text { electos }\end{array}$ \\
\hline PP & & 24.859 & 15 \\
\hline PSOE & & 12.045 & 7 \\
\hline IULV & & 4.685 & 3 \\
\hline EU ERX PREX & & 1.918 & \\
\hline
\end{tabular}

\section{CÁDIZ}

№ Electores:

117.253

№ Votantes:

74.969

№ Votos de candidatura:

73.855

№ Votos en blanco:

840

№ Votos válidos:

74.694

№ Votos nulos:

274

\begin{tabular}{lcc}
\hline Candidaturas & $\begin{array}{c}\text { Votos } \\
\text { obtenidos }\end{array}$ & $\begin{array}{c}\text { No Concejales } \\
\text { electos }\end{array}$ \\
\hline PP & 36.640 & 15 \\
PSOE & 17.201 & 7 \\
IU LV CA & 13.844 & 5 \\
PIE & 737 & \\
PA & 2.589 & \\
Cádiz Agrupación Democrática Independiente & 1.848 \\
PAP & 883 & \\
Falange Española de las JONS & 113 \\
\hline
\end{tabular}




\section{CASTELLÓN}

\begin{tabular}{|c|c|c|c|}
\hline $\begin{array}{l}\text { № Electores: } \\
\text { № Votantes: } \\
\text { № Votos de candidatura: } \\
\text { № Votos en blanco: } \\
\text { № Votos válidos: } \\
\text { № Votos nulos: }\end{array}$ & $\begin{array}{r}110.106 \\
75.677 \\
74.122 \\
999 \\
75.121 \\
556\end{array}$ & & \\
\hline \multicolumn{2}{|c|}{ Candidaturas } & $\begin{array}{c}\text { Votos } \\
\text { obtenidos }\end{array}$ & $\begin{array}{l}\text { No Concejales } \\
\quad \text { electos }\end{array}$ \\
\hline \multicolumn{2}{|l|}{$\mathrm{PP}$} & 40.467 & 16 \\
\hline \multicolumn{2}{|l|}{ PSOE } & 20.180 & 8 \\
\hline \multicolumn{2}{|l|}{ Esquerra Unida Els Verds } & 6.900 & 2 \\
\hline \multicolumn{2}{|c|}{ Unitat del Poble Valencia Grau Unit } & 4.278 & 1 \\
\hline \multicolumn{2}{|c|}{ Unio Valenciana Independents Centristes } & 1.401 & \\
\hline \multicolumn{2}{|l|}{$\operatorname{cDS}$} & 482 & \\
\hline \multirow{2}{*}{\multicolumn{2}{|c|}{$\begin{array}{l}\text { Esquerra Alternativa de Castello } \\
\text { Federación de la Plataforma de }\end{array}$}} & 261 & \\
\hline & & 153 & \\
\hline
\end{tabular}

\section{CIUDAD REAL}

№ Electores:

47.556

№ Votantes:

33.815

№ Votos de candidatura: $\quad 32.991$

№ Votos en blanco:

582

№ Votos válidos:

33.573

№ Votos nulos:

242

\begin{tabular}{lrc}
\hline \multicolumn{1}{c}{ Candidaturas } & $\begin{array}{c}\text { Votos } \\
\text { obtenidos }\end{array}$ & $\begin{array}{c}\text { No Concejales } \\
\text { electos }\end{array}$ \\
\hline PP & 19.332 & 16 \\
PSOE & 8.811 & 7 \\
IU & 3.621 & 2 \\
Unión Centrista & 487 & \\
Partido Regionalista de Castilla-La Mancha & 740 & \\
\hline
\end{tabular}




\section{CÓRDOBA}

№ Electores:

№ Votantes:

№ Votos de candidatura:

№ Votos en blanco:

№ Votos válidos:

№ Votos nulos:
240.362

151.221

148.411

2.302

150.713

508

\begin{tabular}{lrc}
\hline \multicolumn{1}{c}{ Candidaturas } & $\begin{array}{c}\text { Votos } \\
\text { obtenidos }\end{array}$ & $\begin{array}{c}N^{\circ} \text { Concejales } \\
\text { electos }\end{array}$ \\
\hline PSOE de Andalucía & 26.173 & 5 \\
Partido Andaluz del Progreso & 1.815 & 0 \\
PP & 61.619 & 13 \\
IU Los Verdes Convocatoria por Andalucía & 55.948 & 11 \\
Nación Andaluza & 249 & 0 \\
Falange Española de las JONS & 206 & 0 \\
Partido Andalucista & 2.401 & 0 \\
\hline
\end{tabular}

\section{CUENCA}

№ Electores:

№ Votantes:

№ Votos de candidatura:

№ Votos en blanco:

№ Votos válidos:

№ Votos nulos:
35.463

26.633

26.099

385

26.484

149

\begin{tabular}{lrc}
\hline Candidaturas & $\begin{array}{c}\text { Votos } \\
\text { obtenidos }\end{array}$ & $\begin{array}{c}\text { No Concejales } \\
\text { electos }\end{array}$ \\
\hline PP & 13.583 & 11 \\
PSOE & 10.699 & 9 \\
IU de Castilla-La Mancha & 1.381 & 1 \\
Tierra Comunera-Partido Nacionalista Castellano & 133 & 0 \\
Unión del Pueblo Conquense & 303 & 0 \\
\hline
\end{tabular}




\section{GIRONA}

№ Electores:

55.806

№ Votantes:

35.650

№ Votos de candidatura: $\quad 35.049$

№ Votos en blanco:

415

№ Votos válidos:

35.464

№ Votos nulos:

186

\begin{tabular}{lcc}
\hline \multicolumn{1}{c}{ Candidaturas } & $\begin{array}{c}\text { Votos } \\
\text { obtenidos }\end{array}$ & $\begin{array}{c}\text { No Concejales } \\
\text { electos }\end{array}$ \\
\hline PSC-PSOE & 17.628 & 14 \\
PP & 4.255 & 3 \\
Convergencia i Unio & 7.238 & 5 \\
Coalicio Iniciativa per Catalunya-Els Verds & 2.231 & 1 \\
Esquerra Republicana de Catalunya & 3.697 & 2 \\
\hline
\end{tabular}

\section{GRANADA}

№ Electores: $\quad 215.493$

№ Votantes: $\quad 143.592$

№ Votos de candidatura: $\quad 140.937$

№ Votos en blanco: $\quad 2.129$

№ Votos válidos: $\quad 143.066$

№ Votos nulos: $\quad 526$

\begin{tabular}{lrr}
\hline \multicolumn{1}{c}{ Candidaturas } & $\begin{array}{c}\text { Votos } \\
\text { obtenidos }\end{array}$ & $\begin{array}{c}\text { No Concejales } \\
\text { electos }\end{array}$ \\
\hline PP & 73.936 & 15 \\
PSOE-A & 40.483 & 8 \\
IU-LVCA & 22.492 & 4 \\
Partido Andalucista & 1.685 & \\
UNidad Popular de Andalucía & 119 & \\
Federación Andaluza de Independientes & 235 \\
Partido Andaluz de Progreso & 1.581 \\
Falange Española de las JONS & 122 & \\
Partido Nación Andaluza & 141 & \\
Plataforma Independientes de España & 143 & \\
\hline
\end{tabular}




\section{GUADALAJARA}

№ Electores:

51.794

№ Votantes:

38.013

№ Votos de candidatura:

36.915

№ Votos en blanco:

790

№ Votos válidos:

37.705

№ Votos nulos:

308

\begin{tabular}{lrc}
\hline Candidaturas & $\begin{array}{c}\text { Votos } \\
\text { obtenidos }\end{array}$ & $\begin{array}{c}\text { No Concejales } \\
\text { electos }\end{array}$ \\
\hline IU & 7.409 & 5 \\
PSOE & 9.059 & 6 \\
PP & 19.149 & 14 \\
PRGU & 264 & \\
FE de las JONS & 116 & \\
CDS & 281 & \\
\hline
\end{tabular}

\section{HUELVA}

№ Electores:

112.583

No Votantes:

66.157

№ Votos de candidatura:

65.131

№ Votos en blanco:

№ Votos válidos:

65.870

№ Votos nulos:

173

\begin{tabular}{|c|c|c|}
\hline Candidaturas & $\begin{array}{c}\text { Votos } \\
\text { obtenidos }\end{array}$ & $\begin{array}{c}\text { № Concejales } \\
\text { electos }\end{array}$ \\
\hline PP & 27.903 & 12 \\
\hline PSOE & 24.697 & 11 \\
\hline IU & 9.762 & 4 \\
\hline PA & 2.531 & \\
\hline NA & 238 & \\
\hline
\end{tabular}




\section{HUESCA}

\begin{tabular}{|c|c|c|c|}
\hline $\begin{array}{l}\text { № Electores: } \\
\text { № Votantes: } \\
\text { № Votos de candidatura: } \\
\text { № Votos en blanco: } \\
\text { № Votos válidos: } \\
\text { № Votos nulos: }\end{array}$ & $\begin{array}{r}36.376 \\
24.766 \\
24.130 \\
453 \\
24.583 \\
183\end{array}$ & & \\
\hline Candidatura & & $\begin{array}{c}\text { Votos } \\
\text { obtenidos }\end{array}$ & $\begin{array}{c}\text { № Concejales } \\
\text { electos }\end{array}$ \\
\hline IU de Aragón & & 2.271 & 2 \\
\hline PSOE & & 5.268 & 5 \\
\hline PAR & & 7.252 & 6 \\
\hline PP & & 7.444 & 7 \\
\hline PIE & & 501 & 0 \\
\hline CHA & & 1.394 & 1 \\
\hline
\end{tabular}

\section{JAÉN}

№ Electores: $\quad 82.323$

№ Votantes: $\quad 58.969$

№ Votos de candidatura: $\quad 58.038$

№ Votos en blanco: $\quad 712$

№ Votos válidos: $\quad 58.750$

№ Votos nulos: $\quad 219$

\begin{tabular}{lrc}
\hline \multicolumn{1}{c}{ Candidaturas } & $\begin{array}{c}\text { Votos } \\
\text { obtenidos }\end{array}$ & $\begin{array}{c}\text { No Concejales } \\
\text { electos }\end{array}$ \\
\hline Partido Andalucista & 2.330 & \\
IU-LV-CA & 8.143 & 4 \\
PP & 30.938 & 15 \\
Partido Andaluz del Progreso & 224 & \\
PSOE-A & 16.187 & 8 \\
Octubre Socialista & 216 & \\
\hline
\end{tabular}




\section{LA CORUÑ̃A}

\begin{tabular}{lrrr} 
NNo Electores: & 214.711 & \\
№ Votantes: & 135.785 & \\
№ Votos de candidatura: & 133.433 & \\
№ Votos en blanco: & 1.874 & \\
№ Votos válidos: & 135.307 & \\
№ Votos nulos: & 478 & & \\
\hline \multicolumn{1}{c}{ Candidaturas } & Votos & № Concejales \\
& & obtenidos & electos \\
\hline & & 69.705 & 15 \\
\hline PSOE & 3.560 & 2 \\
IU Esquerda Galega & 10.735 & 10 \\
Bloque Nacionalista Galego & & 49.135 & \\
PP & & 298 & \\
Coalición Plataforma Humanista & &
\end{tabular}

\section{LAS PALMAS DE GRAN CANARIA}

$\begin{array}{lr}\text { № Electores: } & 288.712 \\ \text { № Votantes: } & 173.821 \\ \text { № Votos de candidatura: } & 170.522 \\ \text { № Votos en blanco: } & 2.134 \\ \text { № Votos válidos: } & 172.656 \\ \text { № Votos nulos: } & 1.165\end{array}$

\begin{tabular}{|c|c|c|}
\hline Candidaturas & $\begin{array}{c}\text { Votos } \\
\text { obtenidos }\end{array}$ & $\begin{array}{c}\text { № Concejales } \\
\text { electos }\end{array}$ \\
\hline IUC & 11.440 & 2 \\
\hline $\mathrm{CGC}$ & 3.925 & \\
\hline PP & 83.502 & 15 \\
\hline PGC & 10.937 & 2 \\
\hline PSOE & 31.209 & 5 \\
\hline $\mathrm{CC}$ & 28.192 & 5 \\
\hline CDS Unión Centrista & 723 & \\
\hline PH & 594 & \\
\hline
\end{tabular}




\section{LEÓN}

\begin{tabular}{|c|c|c|c|}
\hline $\begin{array}{l}\text { № Electores: } \\
\text { № Votantes: } \\
\text { № Votos de candidatura: } \\
\text { № Votos en blanco: } \\
\text { № Votos válidos: } \\
\text { № Votos nulos: }\end{array}$ & \multirow[t]{2}{*}{$\begin{array}{r}116.333 \\
78.533 \\
76.511 \\
1.517 \\
78.028 \\
505\end{array}$} & & \\
\hline Candidaturas & & $\begin{array}{c}\text { Votos } \\
\text { obtenidos }\end{array}$ & $\begin{array}{c}\text { № Concejales } \\
\text { electos }\end{array}$ \\
\hline U & & 5.051 & 1 \\
\hline PP & & 35.712 & 14 \\
\hline UPL & & 16.888 & 6 \\
\hline PRPL & & 223 & 0 \\
\hline IPL & & 1.360 & 0 \\
\hline Partido de El Bierzo & & 49 & 0 \\
\hline Coalición Plataforma Humanista & & 98 & 0 \\
\hline PSOE & & 17.130 & 6 \\
\hline
\end{tabular}

\section{LLEIDA}

№ Electores:

92.667

№ Votantes:

55.894

№ Votos de candidatura:

55.199

№ Votos en blanco:

515

№ Votos válidos:

55.714

№ Votos nulos:

180

\begin{tabular}{|c|c|c|}
\hline Candidaturas & $\begin{array}{c}\text { Votos } \\
\text { obtenidos }\end{array}$ & $\begin{array}{c}\text { № Concejales } \\
\text { electos }\end{array}$ \\
\hline PSC & 24.454 & 13 \\
\hline $\mathrm{CIU}$ & 13.182 & 7 \\
\hline PP & 9.543 & 5 \\
\hline IC EV & 3.722 & 1 \\
\hline ERC & 3.036 & 1 \\
\hline FREIXES & 978 & 0 \\
\hline LÁSSEM & 139 & 0 \\
\hline CLL & 104 & 0 \\
\hline AIPNI & 41 & 0 \\
\hline
\end{tabular}




\section{LOGROÑO}

№ Electores:

100.131

№ Votantes:

71.179

№ Votos de candidatura:

69.552

№ Votos en blanco:

1.266

№ Votos válidos:

70.818

№ Votos nulos:

361

\begin{tabular}{lcc}
\hline Candidaturas & $\begin{array}{c}\text { Votos } \\
\text { obtenidos }\end{array}$ & $\begin{array}{c}\text { No Concejales } \\
\text { electos }\end{array}$ \\
\hline PP & 36.080 & 15 \\
PSOE & 23.375 & 10 \\
IU & 6.001 & 2 \\
Partido Riojano & 3.159 & \\
AR & 937 & \\
\hline
\end{tabular}

\section{LUGO}

№ Electores: $\quad 72.034$

№ Votantes: $\quad 46.650$

№ Votos de candidatura: $\quad 45.469$

№ Votos en blanco: $\quad 910$

№ Votos válidos: $\quad 46.379$

№ Votos nulos: 271

\begin{tabular}{lrc}
\hline Candidaturas & $\begin{array}{c}\text { Votos } \\
\text { obtenidos }\end{array}$ & $\begin{array}{c}\text { No Concejales } \\
\text { electos }\end{array}$ \\
\hline PP & 21.581 & 13 \\
PS de G-PSOE & 9.080 & 5 \\
BNG & 6.750 & 4 \\
Esquerda Unida-Esquerda Galega & 6.291 & 3 \\
CNG & 1.767 & 0 \\
\hline
\end{tabular}

\section{MADRID}

№ Electores: $\quad 2.529 .476$

№ Votantes: $\quad 1.801 .310$

№ Votos de candidatura: $\quad 1.762 .722$

№ Votos en blanco: $\quad 31.467$

№ Votos válidos: $\quad \quad 1.794 .189$

№ Votos nulos: $\quad 7.121$ 
ANÁLISIS DE LAS ELECCIONES MUNICIPALES Y AUTONÓMICAS DE 28 DE ...

\begin{tabular}{lrr}
\hline \multicolumn{1}{c}{ Candidaturas } & $\begin{array}{c}\text { Votos } \\
\text { obtenidos }\end{array}$ & $\begin{array}{c}\text { No Concejales } \\
\text { electos }\end{array}$ \\
\hline IU & 279.090 & 9 \\
PP & 945.634 & 30 \\
Plataforma Humanista & 1.450 & 0 \\
Falange Española Independiente & 615 & 0 \\
Federación Plataforma Independientes de España & 11.734 & 0 \\
PSOE & 499.435 & 16 \\
Los Verdes-Grupo Verde & 13.013 & 0 \\
Falange España de las JONS & 1.244 & 0 \\
Coalición Nuevo Partido Socialista & 487 & 0 \\
Partido Obrero Revolucionario & 1.097 & 0 \\
Los Verdes Alternativos & 6.073 & 0 \\
Partido Revolucionario de los Trabajadores & 622 & 0 \\
PRIM & 2.228 & 0 \\
\hline
\end{tabular}

\section{MÁLAGA}

№ Electores:

№ Votantes:

416.780

№ Votos de candidatura: $\quad 266.982$

№ Votos en blanco:

269.986

№ Votos válidos:

2.344

№ Votos nulos:

266.982

\begin{tabular}{|c|c|c|}
\hline Candidaturas & $\begin{array}{c}\text { Votos } \\
\text { obtenidos }\end{array}$ & $\begin{array}{c}\text { No Concejales } \\
\text { electos }\end{array}$ \\
\hline PMP & 1.802 & 0 \\
\hline PSOE-A & 56.554 & 7 \\
\hline PIE & 507 & 0 \\
\hline PP & 122.975 & 15 \\
\hline IU-LV-CA & 76.580 & 9 \\
\hline $\mathrm{PH}$ & 191 & 0 \\
\hline VAD & 208 & 0 \\
\hline FE-JONS & 148 & 0 \\
\hline $\mathrm{PA}$ & 5.719 & 0 \\
\hline UPAN & 239 & 0 \\
\hline PAP & 1.505 & 0 \\
\hline UDL & 426 & 0 \\
\hline NA & 128 & 0 \\
\hline
\end{tabular}




\section{MURCIA}

№ Electores:

263.013

№ Votantes:

201.161

№ Votos de candidatura:

198.162

№ Votos en blanco:

2.191

№ Votos válidos:

200.353

№ Votos nulos:

1.016

\begin{tabular}{|c|c|c|}
\hline Candidaturas & $\begin{array}{c}\text { Votos } \\
\text { obtenidos }\end{array}$ & $\begin{array}{c}N^{o} \text { Concejales } \\
\text { electos }\end{array}$ \\
\hline PP & 118.438 & 18 \\
\hline PSOE & 50.279 & 7 \\
\hline IU LVRM & 26.584 & 4 \\
\hline UC CDS & 1.421 & 0 \\
\hline NR & 906 & 0 \\
\hline CEDI & 535 & 0 \\
\hline
\end{tabular}

\section{ORENSE}

$\begin{array}{lr}\text { № Electores: } & 87.505 \\ \text { № Votantes: } & 57.920 \\ \text { № Votos de candidatura: } & 56.830 \\ \text { № Votos en blanco: } & 795 \\ \text { № Votos válidos: } & 57.625 \\ \text { № Votos nulos: } & 295\end{array}$

\begin{tabular}{lrr}
\hline Candidaturas & $\begin{array}{c}\text { Votos } \\
\text { obtenidos }\end{array}$ & $\begin{array}{c}N^{\circ} \text { Concejales } \\
\text { electos }\end{array}$ \\
\hline PIE & 923 & 6 \\
BNG & 11.921 & \\
ADEI-O & 262 & 7 \\
PS de G-PSOE & 13.732 & \\
CG & 1.064 & 14 \\
EU-EG & 2.134 & \\
PP & 26.513 & \\
OV & 253 & \\
PH & 28 & \\
\hline
\end{tabular}




\section{OVIEDO}

\begin{tabular}{|c|c|c|c|}
\hline $\begin{array}{l}\text { № Electores: } \\
\text { № Votantes: } \\
\text { № Votos de candidatura: } \\
\text { № Votos en blanco: } \\
\text { № Votos válidos: } \\
\text { № Votos nulos: }\end{array}$ & $\begin{array}{r}172.341 \\
118.813 \\
116.430 \\
1.776 \\
118.206 \\
607\end{array}$ & & \\
\hline Candidaturas & & $\begin{array}{c}\text { Votos } \\
\text { obtenidos }\end{array}$ & $\begin{array}{c}\text { № Concejales } \\
\text { electos }\end{array}$ \\
\hline PSOE & & 24.783 & 6 \\
\hline AA & & 354 & 0 \\
\hline PAS & & 1.723 & 0 \\
\hline IU & & 13.717 & 3 \\
\hline Verdes & & 669 & 0 \\
\hline CAS & & 1.290 & 0 \\
\hline PP & & 73.462 & 18 \\
\hline LA & & 432 & 0 \\
\hline
\end{tabular}

\section{PALENCIÁ}

\begin{tabular}{|c|c|c|c|}
\hline $\begin{array}{l}\text { № Electores: } \\
\text { № Votantes: } \\
\text { № Votos de candidatura: } \\
\text { № Votos en blanco: } \\
\text { № Votos válidos: } \\
\text { № Votos nulos: }\end{array}$ & $\begin{array}{r}63.009 \\
44.785 \\
43.569 \\
845 \\
44.414 \\
371\end{array}$ & & \\
\hline \multicolumn{2}{|l|}{ Candidaturas } & $\begin{array}{c}\text { Votos } \\
\text { obtenidos }\end{array}$ & $\begin{array}{c}\text { № Concejales } \\
\text { electos }\end{array}$ \\
\hline \multirow{2}{*}{\multicolumn{2}{|c|}{ TC-PNC }} & 238 & \\
\hline & & 1.593 & \\
\hline \multicolumn{2}{|l|}{ PSOE } & 16.919 & 10 \\
\hline \multicolumn{2}{|l|}{ PP } & 20.240 & 13 \\
\hline \multicolumn{2}{|l|}{ IUCL } & 3.890 & 2 \\
\hline \multicolumn{2}{|c|}{ Unidad Regionalista de Castilla y León } & 274 & \\
\hline \multicolumn{2}{|l|}{$\operatorname{CDS}$} & 424 & \\
\hline
\end{tabular}




\section{PALMA}

№ Electores:

245.209

№ Votantes:

142.216

№ Votos de candidatura:

139.317

№ Votos en blanco:

1.972

№ Votos válidos:

141.289

№ Votos nulos:

927

\begin{tabular}{|c|c|c|}
\hline Candidaturas & $\begin{array}{c}\text { Votos } \\
\text { obtenidos }\end{array}$ & $\begin{array}{c}\text { No Concejales } \\
\text { electos }\end{array}$ \\
\hline PP & 63.331 & 15 \\
\hline PSM-NM & 14.587 & 3 \\
\hline EVIB & 6.026 & \\
\hline MV-NPS & 251 & \\
\hline PSOE & 33.200 & 8 \\
\hline PIE & 253 & \\
\hline IU & 13.890 & 3 \\
\hline ERC & 548 & \\
\hline UM & 6.540 & \\
\hline ASI & 691 & \\
\hline
\end{tabular}

\section{PAMPLONA}

№ Electores:

147.041

№ Votantes:

94.879

№ Votos de candidatura: $\quad 83.426$

№ Votos en blanco:

1.955

№ Votos válidos:

85.381

№ Votos nulos:

546

\begin{tabular}{|c|c|c|}
\hline Candidaturas & $\begin{array}{c}\text { Votos } \\
\text { obtenidos }\end{array}$ & $\begin{array}{c}\text { № Concejales } \\
\text { electos }\end{array}$ \\
\hline UPN & 28.687 & 10 \\
\hline CDN & 19.247 & 6 \\
\hline PSN-PSOE & 14.870 & 5 \\
\hline IU EB & 10.917 & 3 \\
\hline $\mathrm{HB}$ & 9.705 & 3 \\
\hline
\end{tabular}




\section{PONTEVEDRA}

$\begin{array}{lr}\text { № Electores: } & 60.295 \\ \text { № Votantes: } & 38.438 \\ \text { № Votos de candidatura: } & 37.481 \\ \text { № Votos en blanco: } & 778 \\ \text { № Votos válidos: } & 38.259 \\ \text { № Votos nulos: } & 179\end{array}$

\begin{tabular}{lcc}
\hline Candidaturas & $\begin{array}{c}\text { Votos } \\
\text { obtenidos }\end{array}$ & $\begin{array}{c}\text { No Concejales } \\
\text { electos }\end{array}$ \\
\hline PP & 15.979 & 11 \\
BNG & 9.719 & 7 \\
PSG-PSOE & 7.361 & 6 \\
PU & 3.363 & 2 \\
EU-EG & 713 & 0 \\
Os Verde de Galicia & 346 & 0 \\
\hline
\end{tabular}

\section{SALAMANCA}

№ Electores:

136.213

№ Votantes:

95.426

№ Votos de candidatura:

93.124

№ Votos en blanco:

1.714

№ Votos válidos:

94.838

№ Votos nulos:

588

\begin{tabular}{|c|c|c|}
\hline Candidaturas & $\begin{array}{c}\text { Votos } \\
\text { obtenidos }\end{array}$ & $\begin{array}{c}\text { № Concejales } \\
\text { electos }\end{array}$ \\
\hline PP & 51.212 & 16 \\
\hline PSOE & 31.431 & 9 \\
\hline $\mathrm{IU}$ & 8.170 & 2 \\
\hline Otros & 2.311 & 0 \\
\hline
\end{tabular}




\section{SANTANDER}

№ Electores:

158.443

№ Votantes:

102.532

№ Votos de candidatura:

№ Votos en blanco:

2.473

№ Votos válidos:

№ Votos nulos:

878

\begin{tabular}{lrc}
\hline \multicolumn{1}{c}{ Candidaturas } & $\begin{array}{c}\text { Votos } \\
\text { obtenidos }\end{array}$ & $\begin{array}{c}N^{\circ} \text { Concejales } \\
\text { electos }\end{array}$ \\
\hline Izquierda Unida de Cantabria & 9.975 & 3 \\
PSOE & 23.961 & 7 \\
FE JONS & 143 & \\
PP & 37.679 & 11 \\
INCA & 909 & \\
CDS & 438 & 3 \\
PRC & 13.014 & 3 \\
UPCA & 12.435 & \\
CR-CA & 627 & \\
\hline
\end{tabular}

SAN SEBASTIÁN-DONOSTIA

№ Electores:

151.102

№ Votantes:

95.379

№ Votos de candidatura: $\quad 92.913$

№ Votos en blanco:

1.937

№ Votos válidos:

94.850

№ Votos nulos:

529

\begin{tabular}{|c|c|c|}
\hline Candidaturas & $\begin{array}{c}\text { Votos } \\
\text { obtenidos }\end{array}$ & $\begin{array}{c}N^{N} \text { Concejales } \\
\text { electos }\end{array}$ \\
\hline IU-EB & 4.975 & 1 \\
\hline Plazandreok & 2.287 & 0 \\
\hline EA & 16.271 & 5 \\
\hline PP & 22.611 & 7 \\
\hline $\mathrm{HB}$ & 13.579 & 4 \\
\hline PSE-EE & 21.677 & 7 \\
\hline Herri-Hats & 186 & 0 \\
\hline EAI-PNV & 11.331 & 3 \\
\hline
\end{tabular}




\section{SANTA CRUZ DE TENERIFE}

$\begin{array}{lr}\text { № Electores: } & 178.467 \\ \text { № Votantes: } & 89.651 \\ \text { № Votos de candidatura: } & 87.700 \\ \text { № Votos en blanco: } & 133.7 \\ \text { № Votos válidos: } & 89.037 \\ \text { № Votos nulos: } & 614\end{array}$

\begin{tabular}{|c|c|c|}
\hline Candidaturas & $\begin{array}{c}\text { Votos } \\
\text { obtenidos }\end{array}$ & $\begin{array}{c}\text { № Concejales } \\
\text { electos }\end{array}$ \\
\hline OC-ATI & 34.879 & 11 \\
\hline PP & 30.149 & 10 \\
\hline PSOE & 13.744 & 4 \\
\hline IU & 6.766 & 2 \\
\hline ATP & 827 & \\
\hline CDS-UC & 610 & \\
\hline AFIT & 430 & \\
\hline Partido La Gente & 295 & \\
\hline
\end{tabular}

\section{SEGOVIA}

№ Electores: $\quad 43.800$

№ Votantes: $\quad 30.297$

№ Votos de candidatura: $\quad 29.193$

№ Votos en blanco: $\quad 792$

№ Votos válidos: $\quad 29.985$

№ Votos nulos: $\quad 312$

\begin{tabular}{lrc}
\hline Candidaturas & $\begin{array}{c}\text { Votos } \\
\text { obtenidos }\end{array}$ & $\begin{array}{c}\text { No Concejales } \\
\text { electos }\end{array}$ \\
\hline PP & 15.815 & 15 \\
PSOE & 6.717 & 6 \\
IU & 4.687 & 4 \\
PIE & 872 & 0 \\
Los Verdes-Grupo Verde & 602 & 0 \\
Partido Regionalista Castellano & 399 & 0 \\
FE JONS & 101 & 0 \\
\hline
\end{tabular}




\section{SEVILLA}

№ Electores:

559.451

№ Votantes:

354.331

№ Votos de candidatura: $\quad 348.108$

№ Votos en blanco:

4.826

№ Votos válidos:

352.934

№ Votos nulos:

1.397

\begin{tabular}{lcc}
\hline \multicolumn{1}{c}{ Candidaturas } & $\begin{array}{c}\text { Votos } \\
\text { obtenidos }\end{array}$ & $\begin{array}{c}\text { No Concejales } \\
\text { electos }\end{array}$ \\
\hline PSOE-A & 100.729 & 10 \\
Voz de Pueblo Andaluz & 549 & 0 \\
PP & 107.446 & 10 \\
PA & 92.417 & 9 \\
IU-LV-CA & 45.416 & 4 \\
Unidad Popular Andaluza & 146 & 0 \\
PAP & 710 & 0 \\
Partido Revolucinario de los Trabajadores & 212 & 0 \\
FE JONS & 236 & 0 \\
Coalición Plataforma Humanista & 247 & 0 \\
\hline
\end{tabular}

\section{SORIA}

№ Electores:

26.716

№ Votantes:

16.287

№ Votos de candidatura: $\quad 15.663$

№ Votos en blanco:

475

№ Votos válidos:

16.138

№ Votos nulos:

149

\begin{tabular}{lcc}
\hline Candidaturas & $\begin{array}{c}\text { Votos } \\
\text { obtenidos }\end{array}$ & $\begin{array}{c}\text { No Concejales } \\
\text { electos }\end{array}$ \\
\hline PP & 7.283 & 11 \\
PSOE & 3.458 & 5 \\
Asi & 1.715 & 2 \\
IU & 1.549 & 2 \\
AVS & 1.110 & 1 \\
UC & 307 & 0 \\
UPS & 241 & 0 \\
\hline
\end{tabular}




\section{TARRAGONA}

№ Electores:

№ Votantes:

№ Votos de candidatura:

№ Votos en blanco:

№ Votos válidos:

№ Votos nulos:
90.602

57.342

56.551

588

57.139

203

\begin{tabular}{lccc}
\hline & Candidaturas & $\begin{array}{c}\text { Votos } \\
\text { obtenidos }\end{array}$ & $\begin{array}{c}\text { No Concejales } \\
\text { electos }\end{array}$ \\
\hline CIU & 25.365 & 13 \\
IC-EV & 4.922 & 2 \\
ERC & 2.455 & 0 \\
PSC-PSOE & 14.385 & 7 \\
PP & 9.424 & 5 \\
\hline
\end{tabular}

\section{TERUEL}

№ Electores:

№ Votantes:

№ Votos de candidatura:

№ Votos en blanco:

№ Votos válidos:

№ Votos nulos:
23.533

15.890

15.470

310

15.780

110

\begin{tabular}{lrc}
\hline Candidaturas & $\begin{array}{c}\text { Votos } \\
\text { obtenidos }\end{array}$ & $\begin{array}{c}N^{\circ} \text { Concejales } \\
\text { electos }\end{array}$ \\
\hline CHA & 821 & 1 \\
PSOE & 5.099 & 7 \\
PAR & 1.497 & 2 \\
PP & 7.144 & 9 \\
IU & 909 & 1 \\
\hline
\end{tabular}




\section{TOLEDO}

\begin{tabular}{|c|c|c|c|}
\hline $\begin{array}{l}\text { № Electores: } \\
\text { № Votantes: } \\
\text { № Votos de candidatura: } \\
\text { № Votos en blanco: } \\
\text { № Votos válidos: } \\
\text { № Votos nulos: }\end{array}$ & $\begin{array}{r}49.327 \\
36.453 \\
35.659 \\
581 \\
36.240 \\
213\end{array}$ & & \\
\hline Candidaturas & & $\begin{array}{c}\text { Votos } \\
\text { obtenidos }\end{array}$ & $\begin{array}{c}\text { № Concejales } \\
\text { electos }\end{array}$ \\
\hline PSOE & & 13.234 & 10 \\
\hline PP & & 17.952 & 13 \\
\hline IU & & 3.789 & 2 \\
\hline Unidad Regional Independiente & & 3.789 & 2 \\
\hline Grupo Verde & & 419 & 0 \\
\hline FE JONS & & 66 & 0 \\
\hline uc & & 170 & 0 \\
\hline
\end{tabular}

\section{VALENCIA}

№ Electores:

627.784

№ Votantes:

458.649

№ Votos de candidatura:

451.694

№ Votos en blanco:

5.371

№ Votos válidos:

457.065

№ Votos nulos:

1.584

\begin{tabular}{lrc}
\hline \multicolumn{1}{c}{ Candidaturas } & $\begin{array}{c}\text { Votos } \\
\text { obtenidos }\end{array}$ & $\begin{array}{c}N^{\circ} \text { Concejales } \\
\text { electos }\end{array}$ \\
\hline PSOE & 110.071 & 8 \\
EU-EV & 67.532 & 5 \\
PP & 223.963 & 17 \\
Partido Republicano Autonomista & 618 & 0 \\
Liga Autónoma Española & 221 & 0 \\
RV & 1.117 & 0 \\
UPV-BN & 4.290 & 0 \\
Esquerra Nacionalista Valenciana & 481 & 0 \\
CDS & 1.645 & 0 \\
Plataforma Humanista & 346 & 0 \\
PIE & 391 & 0 \\
UV-CCV & 41.019 & 3 \\
\hline
\end{tabular}




\section{VALLADOLID}

№ Electores:

272.792

№ Votantes:

195.902

№ Votos de candidatura: $\quad 190.408$

№ Votos en blanco:

3.716

№ Votos válidos:

194.124

№ Votos nulos:

1.519

\begin{tabular}{|c|c|c|}
\hline Candidaturas & $\begin{array}{c}\text { Votos } \\
\text { obtenidos }\end{array}$ & $\begin{array}{c}\text { No Concejales } \\
\text { electos }\end{array}$ \\
\hline PP & 91.876 & 15 \\
\hline PSOE & 65.622 & 10 \\
\hline IU & 26.788 & 4 \\
\hline $\mathrm{Cl}$ & 2.132 & 0 \\
\hline $\mathrm{Al}$ & 1.719 & 0 \\
\hline TC-PNC & 587 & 0 \\
\hline PIE & 529 & 0 \\
\hline URCL & 496 & 0 \\
\hline PC-PE & 341 & 0 \\
\hline FE JONS & 318 & 0 \\
\hline
\end{tabular}

\section{VITORIA-GASTEIZ}

$\begin{array}{lr}\text { № Electores: } & 173.556 \\ \text { № Votantes: } & 107.321 \\ \text { № Votos de candidatura: } & 104.767 \\ \text { № Votos en blanco: } & 1.704 \\ \text { № Votos válidos: } & 106.471 \\ \text { № Votos nulos: } & 850\end{array}$

\begin{tabular}{|c|c|c|}
\hline Candidaturas & $\begin{array}{c}\text { Votos } \\
\text { obtenidos }\end{array}$ & $\begin{array}{c}\text { No Concejales } \\
\text { electos }\end{array}$ \\
\hline $\mathrm{HB}$ & 7.448 & 2 \\
\hline PP & 19.240 & 5 \\
\hline IU EB & 8.856 & 2 \\
\hline EA & 4.951 & 0 \\
\hline PSE EE PSOE & 15.568 & 4 \\
\hline EAJP PNV & 29.978 & 9 \\
\hline UA & 18.726 & 5 \\
\hline
\end{tabular}




\section{ZAMORA}

№ Electores:

51.930

№ Votantes:

34.150

№ Votos de candidatura:

32.980

№ Votos en blanco:

637

№ Votos válidos:

№ Votos nulos:

33.616

533

\begin{tabular}{|c|c|c|}
\hline Candidaturas & $\begin{array}{c}\text { Votos } \\
\text { obtenidos }\end{array}$ & $\begin{array}{c}\text { № Concejales } \\
\text { electos }\end{array}$ \\
\hline PSOE & 11.131 & 9 \\
\hline IU & 3.062 & 2 \\
\hline PP & 17.654 & 14 \\
\hline PREPAL & 798 & \\
\hline $\mathrm{PIZ}$ & 335 & \\
\hline
\end{tabular}

\section{ZARAGOZA}

№ Electores:

497.001

№ Votantes:

333.394

№ Votos de candidatura:

326.113

№ Votos en blanco:

5.655

№ Votos válidos:

331.768

№ Votos nulos:

1.626

\begin{tabular}{lrr}
\hline Candidaturas & $\begin{array}{c}\text { Votos } \\
\text { obtenidos }\end{array}$ & $\begin{array}{c}\text { No Concejales } \\
\text { electos }\end{array}$ \\
\hline PAR & 41.558 & 4 \\
PP & 155.206 & 15 \\
IU Aragón & 44.047 & 4 \\
Unidad Aragonesa & 654 & 0 \\
CHA & 19.783 & 2 \\
PIE & 963 & 0 \\
Federación Independien Trabajadores y Autónomos & 1.237 & 0 \\
FE JONS & 275 & 0 \\
PSOE & 62.390 & 6 \\
\hline
\end{tabular}




\section{III.3. Análisis de los resultados electorales}

Globalmente consideradas, estas elecciones municipales podrian calificarse, y así lo hace muy acertadamente J.I. WERT, como unas verdaderas "elecciones de cambio" ", queriendo expresar con ello que se trata de un cambio cualitativo, más que meramente cuantitativo. En efecto, es evidente que la balanza electoral ha cambiado perceptiblemente de signo, lo que no es sino consecuencia - según la opinión del Vicesecretario General del PP - "de un largo proceso de catarsis incubado por la sociedad española" ${ }^{15}$. El PP gana, en términos absolutos, nada menos que 3.042.196 votos, cifra que, en términos de porcentaje sobre voto válido, supone un incremento de casi diez puntos, ya que pasa del $25,34 \%$ obtenido en las municipales de 1991 a un $35,26 \%$. Fundamentalmente, la victoria de los populares se ha cimentado en los grandes núcleos urbanos, los de población superior a 50.000 habitantes, donde ha cosechado 4.264 .604 sufragios, que - porcentualmente hablandorepresenta un $38,64 \%$ sobre el total de votos válidos. Si este porcentaje se compara con el obtenido en las anteriores elecciones municipales $(27,2 \%)$, cabe observar que el aumento porcentual ha sido de más del $11 \%$. Ahora bien, esta tendencia a la "urbanización" del voto popular no es -como se ha encargado de subrayar J.I. WERT ${ }^{16}$ - completa, por cuanto un $45^{\prime} 44 \%$ de su electorado sigue procediendo de zonas que pueden calificarse como rurales, esto es, núcleos urbanos de población inferior a 50.000 habitantes (véase Cuadro III), siendo además destacable que el crecimiento relativo mayor se ha producido en el tramo constituido por localidades de 20.001 a 50.000 habitantes, donde el aumento de su penetración electoral neta ha sido del $56 \%{ }^{17}$, y que, porcentualmente hablando, la más clara diferencia con el PSOE la establece en poblaciones de menos de 250 habitantes (el $43,65 \%$ frente al $25,19 \%$ ). Subrayemos, por último, que el número total de concejales obtenidos por el PP ha sido de 24.699 ,lo que representa un aumento de 8.959 concejalías respecto de los comicios de 1991.

14 WERT: op. cit., pág. 28.

15 RajoY, M.: Del desencanto a la esperanza, en Cambio 16 cit., pág. 9.

16 Wear: op. cit., pág. 30.

17 Según cálculo efectuado por J.I. WERT en op. cit., pág. 30. La penetración electoral neta viene determinada por el porcentaje de votos obtenidos sobre el total de votos válidos. 


\section{CUADRO III}

Resultados del PP por estratos de población

\begin{tabular}{lrrr}
\hline & \multicolumn{1}{c}{ Votos } & $\%$ & Concejales \\
\hline Núcleos urbanos de hasta 250 habitantes & 92.065 & 43,65 & 4.365 \\
Núcleos urbanos entre 251 y 5.000 habitantes & 1.298 .102 & 33,88 & 14.100 \\
Núcleos urbanos entre 5.001 y 20.000 habitantes & 1.363 .622 & 30,13 & 3.857 \\
Núcleos urbanos entre 20.001 y 50.000 habitantes & 798.854 & 31,13 & 1.184 \\
Núcleos urbanos de más de 50.001 habitantes & 4.264 .604 & 38,64 & 1.193 \\
\hline \multicolumn{1}{c}{ TOTAL .......................7.817.247 } & & 24.699 \\
\hline
\end{tabular}

Fuente: Ministerio de Justicia e Interior. Colección Documentos Electorales n.ำ 5: Elecciones Locales 1995.

Por lo que respecta a la segunda gran fuerza electoral de carácter estatal, el PSOE, no cabe decir otra cosa que, si bien ha sufrido una clara derrota electoral, ésta no ha tenido - según ya hemos significado- los caracteres de "derrumbe" que pronosticaban las encuestas electorales publicadas en los medios de comunicación ${ }^{18}$. De una «derrota digna" la han calificado la mayoría de analistas políticos. Tal suavidad en los términos de la derrota podría decirse que se ha fundamentado principalmente en dos factores: la movilización de última hora (del orden de 3 a 4 puntos de censo, según cálculo de J.I. WERT) del electorado "de baja intensidad» del PSOE, al que antes ya hemos hecho referencia; $y$, de otro lado, la fidelidad observada por su electorado que podríamos calificar de "rural»: poblaciones de menos de 50.000 habitantes, con la salvedad de las de menos de 250 habitantes (donde, según ya quedó constancia, la victoria de los populares ha sido aplastante). Así, en lo que atañe a este segundo factor, cabe observar una apretada victoria socialista en el tramo poblacional comprendido entre 5.001 y 50.000 habitantes (2.302.662 votos frente a los 2.162.476 del PP) y un virtual empate con el PP en el tramo constituido por poblaciones de 251 a 5.000 habitantes (1.290.127 votos frente a los 1.298.102 del PP). Ahora bien, como igualmente ha puesto de relieve J.I. WERT ${ }^{19}$, este fenómeno de la "ruralización» del voto socialista no debe entenderse en términos absolutos, toda vez que el $46,63 \%$ de dicho voto ha sido obtenido todavía en los grandes núcleos urbanos de más de 50.000 habitantes.

18 La encuesta más favorable (la publicada en El País de 21 de mayo de 1995) le concedía al PSOE un voto probable máximo del $28 \%$.

19 WERT: op. cit., pág. 30. 
En concreto, el PSOE ha cosechado una suma total de 6.832.267 sufragios, distribuidos por tramos de población en la forma que puede apreciarse en el Cuadro IV. Tal cifra, que representa un $30,81 \%$ de los votos válidos, le ha servido para hacerse con 21.175 concejalías, por lo que ve disminuido el número de éstas, respecto de los comicios de 1991, en 1.729.

\section{CUADRO IV}

Resultados del PSOE por estratos de población

\begin{tabular}{lrrr}
\hline & \multicolumn{1}{c}{ Votos } & $\%$ & Concejales \\
\hline Núcleos urbanos de hasta 250 habitantes & 53.132 & 25,19 & 1.887 \\
Núcleos urbanos entre 251 y 5.000 habitantes & 1.290 .127 & 33,67 & 12.769 \\
Núcleos urbanos entre 5.001 y 20.000 habitantes & 1.469 .471 & 32,47 & 4.272 \\
Núcleos urbanos entre 20.001 y 50.000 habitantes & 833.191 & 32,47 & 1.257 \\
Núcleos urbanos de más de 50.001 habitantes & 3.186 .346 & 28,87 & 990 \\
\hline TOTAL .....................6.832.267 & & 21.175 \\
\hline
\end{tabular}

Fuente: Ministerio de Justicia e Interior. Colección Documentos Electorales n.o 5: Elecciones Locales 1995.

Por su parte, la tercera gran fuerza electoral del Estado, la coalición Izquierda Unida, ha obtenido un ligero avance, aunque lejos del sorpasso a que se aludía en la campaña electoral. En efecto, los 2.590 .301 sufragios que, en términos absolutos, conforman el peso electoral de IU no representan más que el $11,68 \%$ de los votos válidos emitidos, lo que supone una desventaja de más de 19 puntos porcentuales respecto del adversario «a rebasar». Parece claro que unas desmesuradas perspectivas de ganar nuevos votos ha provocado en IU, tras conocerse los resultados electorales, un cierto sentimiento de derrota, pero la verdad es que tal derrota sólo se ha producido respecto de las expectativas electorales y no respecto de los resultados reales. Así, en comparación con las elecciones municipales de 1991, IU ha cosechado alrededor de un millón de votos más (1.011.940, exactamente) y ha crecido, en términos porcentuales, por encima de tres puntos $(3,30 \%)$. La distribución de sus votos por estratos de población (véase Cuadro V) muestra un acentuado predominio de los núcleos urbanos de más de 50.000 habitantes, tramo en el que se ha concentrado el $60,75 \%$ de los votantes de la coalición. Es en dicho tramo donde se ha cimentado, sin duda, el avance experimentado por IU, avance que -en términos materiales de poder municipal- se traduce en la obtención de 3.497 concejalías, superando en 897 el número de las que le correspondieron en los comicios de 1991. 


\section{CUADRO V}

Resultados de IU por estratos de población

\begin{tabular}{lrrr}
\hline & Votos & $\%$ & Concejales \\
\hline Núcleos urbanos de hasta 250 habitantes & 2.338 & 1,11 & 54 \\
Núcleos urbanos entre 251 y 5.000 habitantes & 223.838 & 5,84 & 1.438 \\
Núcleos urbanos entre 5.001 y 20.000 habitantes & 460.775 & 10,18 & 1.100 \\
Núcleos urbanos entre 20.001 y 50.000 habitantes & 329.541 & 12,84 & 441 \\
Núcleos urbanos de más de 50.001 habitantes & 1.573 .809 & 14,26 & 464 \\
\hline TOTAL ......................2.590.401 & & 3.497 \\
\hline
\end{tabular}

Fuente: Ministerio de Justicia e Interior. Colección Documentos Electorales n. ํ 5: Elecciones Locales 1995.

Según se deduce, pues, de lo expuesto, la pérdida de votos experimentada por el PSOE ha beneficiado claramente, por el flanco derecho del espectro político, al PP, mientras que por la izquierda el trasvase de votos hacia IU ha sido mucho más contenido. Ahora bien, de esa pérdida de votos no sólo se han beneficiado los partidos «estatales», ya que cabe observar un notorio avance, en relación con los anteriores comicios, de las diversas candidaturas independientes que, a lo largo y ancho del mapa político municipal, han competido muy dignamente con las grandes fuerzas políticas nacionales. En este sentido, no es ni mucho menos desdeñable el número de sufragios (726.390) obtenido por los candidatos independientes, que representan -porcentualmente hablando- un 3,28\%.

En las circunscripciones electorales con presencia relevante de partidos nacionalistas, éstos - como ha sucedido desde siempre - han concurrido también muy dignamente a la dura batalla electoral. Las dos grandes fuerzas nacionalistas de Cataluña y País Vasco (la coalición Convergencia y Unión y el Partido Nacionalista Vasco, respectivamente) han ampliado el número total de sus votantes, debido fundamentalmente a la alta tasa participativa, pero han experimentado una ligera variación a la baja respecto de los porcentajes obtenidos en las elecciones locales de 1991. Así, CyU baja desde el 4,85\% de los anteriores comicios al 4,39\%, lo que algunos analistas interpretan como un síntoma de que la coalición liderada por Jordi Pujol ha tocado techo, mientras que otros lo explican por la dificultad que tiene combatir simultáneamente con el mismo discurso el "doble frente" representado por Esquerra Republicana de Catalunya y el Partido Popular ${ }^{20}$. Por 
su parte, el PNV ha descendido desde el $1,60 \%$ de 1991 al $1,41 \%$. Puede decirse, por tanto, que los partidos nacionalistas moderados han mantenido prácticamente sus posiciones, aun con una leve tendencia a la baja. Mayor ha sido, por el contrario, el descenso del nacionalismo radical vasco (Herri Batasuna), que no sólo ha perdido votos en términos porcentuales (del $1,06 \%$ al $0,83 \%$ ), sino también en cifras absolutas, pues ha pasado de ser votada en 1991 por 198.445 ciudadanos a serlo, cuatro años después, por 184.694 y ello a pesar del aumento en el índice de participación. ERC, sin embargo, ha mejorado su posición relativa de 1991, cosechando sus mejores resultados electorales: 204.415 votos, que representan el $0,92 \%$ de los votos válidos. Y lo mismo puede predicarse del Bloque Nacionalista Galego, cuyo crecimiento, basado fundamentalmente en el ámbito rural gallego, parece indudable (del $7,71 \%$ de 1991 al 13,15\%).

Cabe observar, por último, un apreciable descenso en el número de votos que ha ido a parar a los principales partidos regionalistas (Unión para el Progreso de Cantabria, Unió Valenciana, Partido Aragonés y Partido Andalucista), con la notable excepción de Coalición Canaria, que en el ámbito territorial canario ha experimentado una mejora de más de seis puntos porcentuales respecto de las elecciones de 1991. La pérdida de votos sufrida por el Partido Andalucista se justifica, desde luego, por la secesión habida en su seno, que ha dado lugar a la aparición en la escena electoral del Partido Andaluz del Progreso, votado por un buen número de ciudadanos en algunos de los grandes núcleos urbanos de la provincia de Cádiz (particularmente, en Jerez de la Frontera y Algeciras). Un caso muy parejo a éste se ha dado también en Navarra, donde la recién creada (por el ex-presidente autonómico Juan Cruz Alli) Convergencia de Demócratas Navarros ha restado, sobre todo en la capital Pamplona, un importante número de votos a su partido «matriz», la Unión del Pueblo Navarro-Partido Popular. Para terminar, reseñemos, a título de anécdota, el éxito obtenido por el Grupo Independiente Liberal del populista Jesús Gil y Gil, que no sólo reedita en Marbella la mayoría absoluta obtenida en 1991, sino que la amplía a su localidad vecina, Estepona.

En resumen, pues, hay que hablar de un gran vuelco electoral que propicia una masiva llegada al poder municipal del Partido Popular, el cual, tras su triunfo en 42 capitales de provincia ( $y$ en 32 de ellas por mayoría absoluta), aparece como el claro vencedor de estas elecciones municipales. EI PSOE, aun vencido, ha visto mitigada su derrota por el apoyo fiel que le han prestado, sobre todo, las poblaciones menores de 50.000 habitantes. Solamente ha ganado en cuatro capitales de provincia 
(Barcelona, La Coruña, Girona y Lleida) y, de ellas, sólo en una (La Coruña) por mayoría absoluta. Aun así, conserva una importante ventaja sobre su más directo adversario a la izquierda del espectro político, la coalición IU, que todavia se halla lejos de ese histórico sorpasso a que se aludió en campaña. Además de todo ello, la mejoría de las candidaturas independientes y del nacionalismo radical catalán y gallego, el mantenimiento de las posiciones moderadas nacionalistas, que vencen en Tarragona (CyU) y en Bilbao y Vitoria (PNV), y el descenso de Herri Batasuna y de los partidos regionalistas (con la excepción de Coalición Canaria) han constituido los focos de atención preferentes en estas elecciones locales de 1995.

\section{LAS ELECCIONES AUTONÓMICAS}

\section{IV.1. Participación}

Al igual que en los comicios municipales, también en estas elecciones la polarización provocada por la campaña electoral ha determinado una muy alta participación de los ciudadanos españoles. Han sido, en efecto, 12.539.044 los electores que ejercieron su derecho de sufragio, cifra que viene a representar un $72,47 \%$ del censo electoral convocado. Tal porcentaje es superior, como se ve, al habido en las municipales y supera en más de siete puntos al de los anteriores comicios autonómicos de 1991 (que fue del $65 \%$ ), lo que da idea del gran interés despertado por la convocatoria electoral.

La participación más alta se ha registrado en Castilla-La Mancha, donde ha sido rebasado en casi seis puntos $(78,83 \%)$ el porcentaje medio global, mientras que las más bajas cifras de participación corresponden a las dos Comunidades insulares, ambas por debajo del $65 \%$, si bien es en Baleares - con un $36,57 \%$ de abstención- donde se alcanza el mayor índice de atonía electoral, superando en casi un punto el porcentaje de abstención habido en Canarias, que es del 35,80\% (véase Cuadro VI, donde se reflejan los índices de abstención de las tres últimas elecciones autonómicas).

Demuestra, pues, la estadística que -con la pequeña excepción de las Comunidades Autónomas insulares- la llamada de 1995 a las urnas 
autonómicas ha atraído, en muy generosa medida, a los convocados al ejercicio del voto, fenómeno este que, si bien puede explicarse, como hacen F. PALLARÉS y J. SOLER ${ }^{21}$, por la ubicación de estas elecciones en el marco de un proceso de cambio político, no deja de ser, por otra parte, un claro sintoma del profundo asentamiento que, en la conciencia ciudadana, han conseguido tanto el régimen democrático como la fórmula sui generis de distribución territorial del poder que auspicia la Constitución española de 1978.

\section{CUADRO VI}

Evolución de la abstención por CC.AA.

\begin{tabular}{lccc}
\hline CC. AA. & $A-1987$ & $A-1991$ & $A-1995$ \\
\hline Aragón & 30,3 & 35,6 & 28,9 \\
Asturias & 33,4 & 40,9 & 30,6 \\
Baleares & 33,1 & 39,6 & 36,6 \\
Canarias & 34,6 & 38,3 & 35,8 \\
Cantabria & 23,7 & 27,4 & 26,0 \\
Castilla y León & 25,9 & 32,4 & 26,5 \\
Castilla-La Mancha & 24,0 & 29,0 & 21,2 \\
Extremadura & 25,6 & 29,0 & 21,7 \\
Madrid & 30,5 & 41,2 & 29,6 \\
Murcia & 27,4 & 32,8 & 24,7 \\
Navarra & 27,1 & 33,3 & 31,6 \\
La Rioja & 27,6 & 31,1 & 23,8 \\
C. Valenciana & 24,7 & 30,8 & 24,0 \\
\hline TOTAL & 28,2 & 35,0 & 27,1 \\
\hline Fuente: Pallarés y Soler. & & & \\
\hline
\end{tabular}

21 Pallarés, F. y Soler, J.: op. cit., pág. 550. 


\section{IV.2. Resultados electorales}

\section{ARAGÓN \\ (Elecciones a Cortes Generales)}

Censo: $\quad 993.975$

Votantes: $\quad 706.954$

Abstenciones: $\quad 287.021$

Votos válidos: $\quad 691.646$

Votos en blanco: $\quad 11.098$

Votos nulos: $\quad 4.210$

\begin{tabular}{lrrc}
\hline Partidos & Votos & \% s/Noto & Escaños \\
\hline PP & 263.524 & 37,28 & 27 \\
PSOE & 180.728 & 25,56 & 19 \\
IU & 64.685 & 9,15 & 5 \\
PAR & 143.573 & 20,31 & 14 \\
CHA & 35.419 & 5,01 & 2 \\
Otros & 3.717 & 0,47 & 0 \\
\hline
\end{tabular}

Fuente: Junta Electoral de Aragón (B.O.A. n.ำ 74, de 21/06/1995)

\section{ASTURIAS}

(Elecciones a la Junta General del Principado)

Censo:

Votantes:

Abstenciones:

Votos válidos:

Votos en blanco:

Votos nulos:
944.949

655.469

289.480

648.677

7.647

6.792

\begin{tabular}{lccc}
\hline Partidos & Votos & $\%$ s Noto & Escaños \\
\hline PP & 272.396 & 41,6 & 21 \\
PSOE & 219.506 & 33,5 & 17 \\
IU & 106.545 & 16,3 & 6 \\
PAST & 20.659 & 3,2 & 1 \\
CDS & 11.568 & 1,8 & - \\
Otros & 10.356 & 1,6 & - \\
\hline
\end{tabular}

Fuente: Junta Electoral Provincial de Asturias. B.O.J.G. n.o 9, de 31/06/1995. 


\section{CANARIAS \\ (Elecciones al Parlamento de Canarias)}

Censo:

1.248 .575

Votantes:

805.321

Abstenciones:

443.254

Votos válidos:

797.059

Votos en blanco:

9.078

Votos nulos:

4.548

\begin{tabular}{lrrc}
\hline Partidos & Votos & $\%$ s/Voto & Escaños \\
\hline CC & 261.424 & 32761 & 21 \\
PP & 247.609 & 30,89 & 18 \\
PSOE & 183.969 & 22,95 & 16 \\
IU & 40.614 & 5,07 & - \\
PCN & 26.878 & 3,35 & 4 \\
Otros & 27.487 & 3,43 & 1 \\
\hline
\end{tabular}

Fuente: Junta Electoral de Canarias. B.O.C. n. ${ }^{\circ} 108$, de 18/08/1995.

\section{CANTABRIA \\ (Elecciones a la Asamblea)}

Censo:

435.752

Votantes:

322.654

Abstenciones:

113.098

Votos válidos:

320.032

Votos en blanco:

6.186

Votos nulos:

2.622

\begin{tabular}{lrcc}
\hline Partidos & Votos & $\%$ sNoto & Escaños \\
\hline PP & 104.008 & 32,24 & 13 \\
PSOE & 80.464 & 24,94 & 10 \\
UPCA & 53.191 & 16,49 & 7 \\
PRC & 46.587 & 14,44 & 6 \\
IU & 23.563 & 7,30 & 3 \\
Otros & 6.033 & 1,87 & - \\
\hline
\end{tabular}

Fuente: Junta Electoral Provincial de Cantabria. B.O.C n. 119, de 15/06/1995. 


\section{CASTILLA Y LEÓN \\ (Elecciones a Cortes de Castilla y León)}

Censo:

2. 119.498

Votantes:

1.556 .979

Abstenciones:

562.519

Votos válidos:

1.543 .068

Votos en blanco:

28.284

Votos nulos:

13.911

\begin{tabular}{lccc}
\hline Partidos & Votos & \% s/Voto & Escaños \\
\hline PP & 805.553 & 51,74 & 50 \\
PSOE & 458.447 & 29,44 & 27 \\
IU & 147.777 & 9,49 & 5 \\
UPL & 39.425 & 2,53 & 2 \\
Otros & 72.676 & 4,67 & - \\
\hline
\end{tabular}

\section{CASTILLA-LA MANCHA (Elecciones a la Asamblea)}

Censo: $\quad 1.352 .958$

Votantes: $\quad 1.066 .571$

Abstenciones: $\quad 286.387$

Votos válidos: $\quad 1.058 .874$

Votos en blanco: $\quad 11.128$

Votos nulos: $\quad 7.697$

\begin{tabular}{lrcc}
\hline Partidos & Votos & \% s/Voto & Escaños \\
\hline PSOE & 483.488 & 45,37 & 24 \\
PP & 469.127 & 43,98 & 22 \\
IU & 80.482 & 7,55 & 1 \\
Otros & 14.249 & 1,34 & - \\
\hline
\end{tabular}

Fuente: Junta Electoral de Castilla-La Mancha. B.O.C.M. n. ${ }^{\circ} 29$, de 16/06/1995. 


\section{EXTREMADURA \\ (Elecciones a la Asamblea)}

Censo:

845.728

Votantes:

662.444

Abstenciones: $\quad 183.284$

Votos válidos: $\quad 658.069$

Votos en blanco: $\quad 5.804$

Votos nulos: $\quad 4375$

\begin{tabular}{lrcc}
\hline Partidos & Votos & \% s/Noto & Escaños \\
\hline PSOE & 289.149 & 43,65 & 31 \\
PP & 259.703 & 39,20 & 27 \\
UU & 69.387 & 10,47 & 6 \\
CEX & 25.168 & 3,80 & 1 \\
Otros & 8.858 & 1,34 & - \\
\hline
\end{tabular}

Fuente: Junta Electoral de Extremadura. BOE n. 68 , de 10/06/1995.

\section{ISLAS BALEARES \\ (Elecciones al Parlament de les llles Balears)}

Censo:

594.687

Votantes:

377.943

Abstenciones: $\quad 216.744$

Votos válidos: $\quad 375.572$

Votos en blanco: $\quad 5.100$

Votos nulos: $\quad 2.371$

\begin{tabular}{lccc}
\hline Partidos & Votos & $\%$ s/Noto & Escaños \\
\hline PP & 168.156 & 44,58 & 30 \\
PSOE & 90.008 & 23,86 & 16 \\
PSM & 47.337 & 12,55 & 6 \\
IU & 24.820 & 6,58 & 3 \\
UM & 19.966 & 5,29 & 2 \\
Otros & 20.185 & 2,35 & 2 \\
\hline
\end{tabular}

Fuente: Junta Electoral de las Islas Baleares. B.O.C.A.I.B. n. ${ }^{\circ} 74$, de 10/06/1995. 


\section{LA RIOJA \\ (Elecciones a la Diputación General)}

Censo: $\quad 218.519$

Votantes: $\quad 166.422$

Abstenciones: $\quad 52.097$

Votos válidos: $\quad 165.252$

Votos en blanco: $\quad 2.856$

Votos nulos: $\quad 1.170$

\begin{tabular}{lccc}
\hline Partidos & Votos & $\%$ sNoto & Escaños \\
\hline PP & 81.703 & 49,09 & 17 \\
PSOE & 56.335 & 33,85 & 12 \\
IU & 11.921 & 7,16 & 2 \\
PR & 11.069 & 6,65 & 2 \\
AR & 1.368 & 0,82 & - \\
\hline
\end{tabular}

Fuente: Junta Electoral de La Rioja. B.O.L.R. n. 73, de 13/06/1995.

MADRID

(Elecciones a la Asamblea de Madrid)

Censo: $\quad 4.129 .852$

Votantes: $\quad 2.907 .141$

Abstenciones: 1.222 .711

Votos válidos: $\quad 2.896 .176$

Votos en blanco: $\quad 38.763$

Votos nulos: $\quad 10.964$

\begin{tabular}{lrcc}
\hline Partidos & \multicolumn{1}{c}{ Votos } & \% sNoto & Escaños \\
\hline PP & 1.476 .442 & 50,97 & 54 \\
PSOE & 860.726 & 29,71 & 32 \\
IU & 464.167 & 16,02 & 17 \\
Otros & 56.079 & 3,30 & - \\
\hline
\end{tabular}

Fuente: Junta Electoral de Madrid. 


\section{Murcia}

(Elecciones a la Asamblea de Regional)

Censo:

847.967

Votantes:

638.297

Abstenciones:

209.670

Votos válidos:

632.831

Votos en blanco:

7.033

Votos nulos:

5.466

\begin{tabular}{lrcc}
\hline Partidos & Votos & $\%$ s/Noto & Escaños \\
\hline PP & 330.514 & 51,78 & 26 \\
PSOE & 201.659 & 31,59 & 15 \\
IU & 78.875 & 12,36 & 4 \\
Otros & 14.750 & 2,30 & - \\
\hline
\end{tabular}

Fuente: Acta de la Junta Electoral de Murcia de 2/06/1995.

\section{NAVARRA \\ (Elecciones al Parlamento de Navarra)}

Censo:

437.797

Votantes:

299.545

Abstenciones:

138.252

Votos validos:

297.179

Votos en blanco:

5.761

Votos nulos:

2.366

\begin{tabular}{lccc}
\hline Partidos & Votos & $\%$ s Noto & Escaños \\
\hline UPN & 93.163 & 31,10 & 17 \\
PSOE & 62.021 & 20,71 & 11 \\
CDN & 55.153 & 18,41 & 10 \\
HB & 27.404 & 11,32 & 5 \\
IU & 27.773 & 9,27 & 5 \\
EA & 13.568 & 4,53 & 2 \\
Otros & 12.336 & 4,12 & - \\
\hline
\end{tabular}

Fuente: Junta Electoral de Navarra. Acta de 5/06/1995. 


\section{COMUNIDAD VALENCIANA \\ (Elecciones a Cortes de Valencia)}

Censo:

3.129 .851

Votantes:

2.380 .814

Abstenciones:

749.037

Votos válidos:

2.367 .600

Votos en blanco:

24.864

Votos nulos:

13.214

\begin{tabular}{lrrc}
\hline Partidos & \multicolumn{1}{c}{ Votos } & $\%$ s/Voto & Escaños \\
\hline PP & 1.013 .859 & 42,64 & 42 \\
PSOE & 804.463 & 33,83 & 32 \\
IU & 273.030 & 11,48 & 10 \\
UV & 165.956 & 6,98 & 5 \\
Otros & 85.428 & 3,47 & - \\
\hline
\end{tabular}

Fuente: Junta Electoral de la Comunidad Valenciana. D.O.G.V. n. ${ }^{2} 4498$, de 22/06/95.

\section{IV.3. Análisis de los resultados electorales}

Si bien la coincidencia cronológica de elecciones locales y autonómicas hace que en ambas «las corrientes de dinámica de voto se expresen en el mismo sentido y con parecida intensidad" ${ }^{22}$, de tal manera que entre los respectivos resultados electorales no suelen darse grandes diferencias, en las elecciones autonómicas aparecen, sin embargo, ciertos factores (por ejemplo, la inexistencia de candidaturas independientes, el carisma o el éxito gestor de los presidentes autonómicos en ejercicio o la mayor intensidad del sentimiento nacionalista o regionalista en los votantes) que, de algún modo, contribuyen a dotarlas de algunos matices específicos respecto de las municipales. Asi, si se realiza un estudio comparativo de los porcentajes de voto obtenidos por las distintas fuerzas políticas en una y otra elección, cabe observar que las diferencias de porcentaje fluctúan normalmente dentro de un margen bastante estrecho (alrededor de un $2 \%$ en más o en menos), pero siempre existen casos concretos donde la fluctuación supera ese estrecho

22 WERT, op. cit., pág. 34. 
margen por alguna de las razones enunciadas, lo que contribuye, sin duda, como ya advertíamos, a dotar de cierta especificidad a las elecciones autonómicas. Uno de estos casos es, por ejemplo, el del PSOE en Castilla-La Mancha, donde la relevante personalidad de su Presidente autonómico, José Bono, ha conseguido arrastrar un $6,40 \%$ más de votos socialistas que en las elecciones municipales celebradas en la misma circunscripción. Otro caso similar es el de Coalición Canaria, que ha visto aumentado sus sufragios en el $6,21 \%$ respecto de las elecciones locales, lo que puede interpretarse como la lógica consecuencia de una mayor intensidad del sentimiento regionalista canario a la hora de elegir a los que van a encargarse de sus asuntos autonómicos. Parecidas consideraciones pueden predicarse también del Partido Regionalista de Cantabria $(+4,16 \%)$ o de la Unión del Pueblo Navarro $(+4,63 \%)$.

No obstante, salvados esos pequeños matices diferenciadores de las elecciones autonómicas, que permiten hablar de la Comunidad Autónoma como "definidora de una arena política específica» ${ }^{23}$ y que provocan las coyunturales consecuencias que acabamos de exponer, lo cierto es que los resultados electorales autonómicos, globalmente considerados, arrojan una similar conclusión a la obtenida en las municipales, es decir, un claro triunfo del PP, una digna derrota socialista y un moderado avance de la coalición IU.

Es, en efecto, el PP la fuerza política que aparece como neta triunfadora: vence con mayoría absoluta en cinco Comunidades (Baleares, Castilla y León, La Rioja, Madrid y Murcia) y, sin ella, en otras cinco (Aragón, Asturias, Cantabria, Navarra ${ }^{24}$ y Comunidad Valenciana). Además de ello, experimenta un notable aumento de votos en las tres Comunidades restantes, obteniendo doce escaños más en el Parlamento canario (de los seis de 1991 a los dieciocho actuales), cuatro más en las Cortes de Castilla-La Mancha (de 18 a 22) y ocho más en la Asamblea extremeña (de 19 a 27). En total, el número de sufragios obtenidos por el PP es de 5.585.757, lo que representa un porcentaje del 44,54 sobre la cifra global de votantes y tal cosecha de votos le va a permitir ocupar, de los 786 escaños que suman todas las asambleas legislativas autonómicas, un total de 364. La ganancia final del PP, en relación con las elecciones autonómicas de 1991, puede calificarse, por tanto, de sustanciosa: 2.205 .359 votos y 97 escaños más, y

23 Pallarés y Soler: op. cit., pág. 552.

24 En esta Comunidad Foral se presenta la Unión del Pueblo Navarro, partido federado al Partido Popular. 
en porcentaje sobre el total de votos, sube casi trece puntos (del 31,75 al ya citado 44,54$)$.

Por su parte, el PSOE sólo logra el triunfo, si bien con menos votos que en 1991, en Castilla-La Mancha y Extremadura. Por mayoría absoluta en la primera de ellas (24 escaños) y con mayoría relativa en la segunda. En las demás Comunidades la pérdida de votos es general, tanto en términos absolutos (con las únicas excepciones de Asturias y Madrid, donde la mayor participación le permite obtener una cifra un poco más amplia de votos que en 1991), como relativos, con unos porcentajes que fluctúan dentro de un amplio margen (desde el $33,85 \%$ obtenido en La Rioja hasta el $20,71 \%$ de Navarra). La cifra global de votos del PSOE se sitúa en 3.971.363, representando un $31,67 \%$ del total de sufragios y permitiéndole obtener 262 escaños en los trece Parlamentos autonómicos que se constituyen. Por tanto, la pérdida en relación con las anteriores elecciones autonómicas debe quedar fijada en 177.623 votos (cifra que, aun no siendo importante, debe valorarse en consideración al aumento de la participación electoral) y 76 escaños. Porcentualmente hablando, baja un poco más de siete puntos (del $38,97 \%$ al citado $31,67 \%$ ).

Tras el PP, la segunda fuerza política de carácter estatal que experimenta un avance respecto de las elecciones de 1991 es —como ya quedó reflejado- la coalición IU, si bien lo moderado de su progresión provocó una general insatisfacción en sus dirigentes por las desmesuradas expectativas de victoria que se habian creado durante la campaña electoral. Tal avance puede condensarse en las siguientes cifras: 1.413 .639 votos (esto es, 676.346 más que en 1991), que representan un $11,27 \%$ del total $(6,92 \%$ en 1991) y que le permiten adjudicarse 67 escaños (es decir, casi el doble de los 34 escaños de 1991). Aun teniendo en cuenta el mayor índice de participación registrado en estas elecciones, dichas cifras, objetivamente hablando, deben ser calificadas como satisfactorias.

La Comunidad Autónoma canaria constituye, por último, la única circunscripción donde se registra la victoria de una fuerza política distinta del PP y del PSOE. Nos referimos, por supuesto, a Coalición Canaria que, con los 261.424 votos obtenidos (que representan un 32,61 del total), resulta el claro vencedor de las elecciones al Parlamento canario, con una diferencia muy escasa respecto del PP y a bastante distancia de los socialistas. Esta cifra de votos le permite adjudicarse 21 escaños de los 60 de que se compone la Cámara legislativa canaria. En este mismo contexto, es de resaltar los cuatro escaños obtenidos por otra fuerza nacionalista, la Plataforma Canaria Nacionalista, que recoge 26.878 votos. 
Sobre la base de los datos expuestos, parece obligado predicar de las elecciones autonómicas de 1995 el mismo carácter que se atribuía a sus coetáneas municipales, esto es, el de tratarse de unas «elecciones de cambio", toda vez que propician un verdadero cambio cualitativo en el panorama político español a su nivel autonómico. En efecto, con la salvedad de la Comunidad Autónoma canaria, continúa produciéndose un generalizado fenómeno de concentración de voto en los dos grandes partidos estatales, pero esta vez, al contrario de lo que ha venido ocurriendo desde 1979, el gran favorecido es el PP y no el PSOE. El retroceso electoral de este último le supone, lógicamente, una importante pérdida del poder institucional y económico ostentado hasta ahora, poder que pasa casi en su totalidad a las manos de su principal adversario político, el PP, para el que, sin duda, estas elecciones, como las municipales, no constituyen sino un hito más a inscribir dentro del proceso general de cambio que, iniciado en 1993, debe desembocar en la democrática conquista del poder político estatal. Obsérvese en esto el paralelismo con la evolución seguida en su momento por el PSOE, que, sólo tras conseguir el poder municipal y autonómico en las elecciones de 1979, pudo acceder tres años más tarde al último bastión en la conquista del poder político, esto es, la siempre codiciada gobernación del Estado.

\section{IV.4. Consecuencias políticas post-electorales}

La primera y más relevante consecuencia política del resultado electoral viene constituida, sin duda, por la considerable modificación que experimenta el mapa autonómico. Pasan a ser gestionadas por el PP seis Comunidades Autónomas antes regidas por el PSOE: La Rioja, Madrid, Murcia, Asturias, Aragón y Comunidad Valenciana. En las tres primeras, accederá al gobierno sin mayores dificultades, pues obtuvo la mayoría absoluta; en las dos últimas, cuenta con el apoyo de partidos regionalistas (Partido Aragonés Regionalista y Unió Valenciana, respectivamente); y en Asturias es donde su gobierno, de mayoría relativa, resulta más inestable, ya que un futuro acuerdo de gobierno entre PSOE e IU -que, en principio, no se ha conseguido- podría terminar con él. Además de ello, el PP no sólo mantiene su aplastante mayoria y su poder institucional en las Comunidades de Baleares y Castilla y León, sino que también, tras acordar un gobierno de coalición con el Partido Regionalista Cántabro, arrebata en Cantabria el poder autonómico a su antiguo aliado, la Unión 
para el Progreso de Cantabria del ex-presidente Juan Hormaechea (cuya candidatura como cabeza de lista quedó excluida por una decisión de la Junta Electoral Central, tomada apenas siete horas antes de la apertura de los colegios electorales). Por el contrario y a pesar de contar con la mayoría relativa, UPN-PP no va a ostentar el poder en Navarra, al alcanzarse un acuerdo de gobierno entre PSN-PSOE, Convergencia de Demócratas Navarros (el partido creado por el ex-presidente Juan Cruz Alli) y Eusko Alkartasuna. Por su parte, el PSOE conserva el gobierno en Castilla-La Mancha y Extremadura, si bien en ésta solamente como mayor minoría, por lo que un hipotético pacto «contra natura» entre el PP e IU podría arrebatárselo. En Canarias, por último, accede al poder Coalición Canaria, con un gobierno de mayoría relativa apoyado por el PP. Debe aclararse, no obstante, que a quien reemplaza en el poder es a un gobierno de coalición integrado por las mismas fuerzas políticas que son ahora socios en la propia Coalición Canaria, ya que ésta fue creada «ad hoc» para presentarse a estas elecciones como fuerza unitaria.

Así pues, el nuevo mapa autonómico resultante de las elecciones se reviste de un tinte claramente hegemónico por parte del PP, que gobierna en diez Comunidades Autónomas (las nueve antecitadas más Galicia), apoya al Gobierno en otra (Canarias) y se mantiene en la oposición en las seis restantes (Andalucía, Castilla-La Mancha, Cataluña, Extremadura, Navarra y País Vasco). A ese mapa autonómico ( $y$, por supuesto, también municipal) "volcado a ıa derecha" viene a contraponerse un Gobierno central en manos de un debilitado PSOE, lo que origina una peculiar situación política que, rememorando a la Francia de Mitterand, ha sido definida por algún comentarista de la prensa diaria como "la versión española de la cohabitación» ${ }^{25}$.

Una segunda consecuencia de estas elecciones es la variación en la composición del Senado, ya que una parte de sus escaños corresponde asignarlos a los Parlamentos autonómicos (art. $69.5 \mathrm{CE}$ ). Así pues, como resultado de la nueva configuración de éstos, el número de escaños que corresponde a cada partido ha variado respecto del existente inmediatamente después de las elecciones generales de 1993, debiendo tenerse en cuenta no sólo las elecciones ahora analizadas, sino también las autonómicas gallegas de 1993 y las andaluzas y vascas de 1994. De esta forma, en el nuevo Senado cuenta el PP con 113 escaños (93 electos y 20 por 
designación autonómica), aumentando en siete respecto de la situación anterior, mientras que el PSOE tiene un total de 111 escaños (96 electos y 15 por designación autonómica), lo que le supone una pérdida de cuatro senadores. Por Grupos parlamentarios, los 256 escaños del Senado quedan, pues, distribuidos de la forma siguiente:

$\begin{array}{lr}\text { G.P. Popular: } & 113 \\ \text { G.P. Socialista: } & 111 \\ \text { G.P. Catalán (C y U): } & 15 \\ \text { G.P. Mixto: } & 7 \\ \text { G.P. Vasco (PNV): } & 5 \\ \text { G.P. Canario (CC): } & 5\end{array}$

Los siete senadores que componen el Grupo Mixto pertenecen, a su vez, a los siguientes partidos y coaliciones: Convergencia de Demócratas Navarros (1), Eusko Alkartasuna (1), Herri Batasuna (1), Izquierda Unida (2), Partido Independiente de Lanzarote (1) y Unió Valenciana (1).

A tenor de los datos expuestos, la mayoría parlamentaria en el Senado, aun siendo relativa, la ostenta ahora el PP, por lo que se produce el curioso hecho de que en cada una de las dos Cámaras legislativas españolas existe una mayoría diferente. Por ello, cabría pensar en un juego de contrapesos en la actuación de una y otra mayorías. Esta posibilidad no es, sin embargo, demasiado real, toda vez que, dado el bicameralismo imperfecto que consagra nuestra Constitución de 1978, resulta muy difícil, como subrayan PALLARÉS y SOLER, que "se pueda configurar [en el Senado] una mayoría más o menos estable que contrarreste a la del Congreso" ${ }^{26}$. Pero, aun así, no se debe dejar de tener en cuenta que la Cámara Alta española "posee instrumentos de control del Gobierno y del proceso legislativo que pueden ser muy útiles en la labor de oposición» ${ }^{27}$.

La tercera y última consecuencia de los comicios autonómicos viene constituida asimismo por una modificación en la composición de otro órgano estatal que, si bien no alcanza el nivel institucional del Senado, sí tiene una importancia fundamental a la hora de fijar la política de financiación autonómica. Nos referimos, claro es, al Consejo de Política Fiscal y Financiera, constituido por los Ministros de Economía y Hacienda

26 Pallarés y Soler, op. cit., pág. 562.

27 Ibídem. 
y de las Administraciones Públicas y -en representación de las Comunidades Autónomas- por los respectivos Consejeros de Hacienda. En este organismo el PP también alcanza, lógicamente, la mayoría (con diez Consejeros), lo que debe permitirle dirigir, de acuerdo con sus propios criterios, la discusión que se avecina sobre el futuro modelo de financiación autonómica. No debe olvidarse el papel clave jugado por este Consejo en las negociaciones entre PSOE y CyU para alcanzar el pacto que permitiría la estabilidad de un gobierno socialista de minoría tras las elecciones generales de 1993. La cesión del 15\% del IRPF a las Comunidades Autónomas fue, por ejemplo, una de las decisiones tomadas por dicho Consejo (con la oposición, por cierto, de los Consejeros autonómicos del PP). Pues bien, a partir de la nueva configuración del Consejo, toda la capacidad de iniciativa y de gestión de los temas de financiación autonómica pasa a estar por entero en las manos del PP, quedando completamente anulada la que hasta entonces tenían PSOE y Convergencia.

\section{LAS ELECCIONES EN CEUTA Y MELILLA}

A caballo entre lo municipal y lo autonómico, estas primeras elecciones a las respectivas Asambleas de las ciudades autónomas de Ceuta y Melilla se han caracterizado fundamentalmente por dos rasgos distintivos: la concurrencia de partidos mayoritariamente integrados por musulmanes (Coalición Electoral Musulmana, en Ceuta, y Coalición por Melilla), junto a diversos partidos de índole local; $y$, en segundo lugar, por lo que se refiere a los partidos de ámbito nacional, la presencia puramente testimonial de la que es la tercera fuerza política, es decir, la coalición Izquierda Unida (a la que sólo votaron en ambas ciudades un total de 1.225 electores, no resultando elegido ninguno de sus candidatos). Pero, junto a tales rasgos específicos, nos encontramos también en ellas con lo que ha sido la tónica general de las elecciones locales y autonómicas coetáneamente celebradas, esto es, el claro triunfo del PP y la subsiguiente derrota socialista, que queda en Melilla como el segundo partido más votado, mientras que en Ceuta baja hasta el cuarto lugar, si bien mejorando, curiosamente, los resultados - tanto absolutos como relativos-obtenidos en esta ciudad en las pasadas elecciones municipales de 1991. El papel de los dos partidos musulmanes antecitados ha sido bastante dispar: mientras que Coalición por Melilla consigue un satisfactorio resultado (4.012 votos, que representan un $15,47 \%$ del total de votos válidos, y 4 escaños), la Coalición 
Electoral Musulmana no obtiene en Ceuta ningún escaño para su candidatura. Respecto de los partidos locales, hay que registrar un fuerte descenso de votos para Progreso y Futuro de Ceuta, que pasa de los 9.420 votos $(37,26 \%)$, que le dieron la victoria en 1991, a los actuales 5.778 (20,07\%), y para el Partido Nacionalista de Melilla, que pierde 772 votos y casi cinco puntos porcentuales (del 8,60\% de 1991 al 3,83\%). Sube, por el contrario, otro partido local como es Ceuta Unida (del $9,89 \%$ al $14,49 \%$ ) y, en Melilla, la Unión del Pueblo Melillense, que se presentaba por primera vez a la elección, consigue dos escaños.

En detalle, los resultados electorales, según la publicación ordenada por la Junta Electoral Central en el Boletín Oficial del Estado n. $\stackrel{0}{173 / 1995}$, de 21 de julio, han sido los siguientes:

\section{CEUTA}

№ Electores:

50.945

№ Votantes:

28.911

№ Votos de candidatura: $\quad 28.457$

№ Votos en blanco:

282

№ Votos válidos:

28.739

№ Votos nulos:

122

\begin{tabular}{|c|c|c|}
\hline Candidaturas & $\begin{array}{c}\text { Votos } \\
\text { obtenidos }\end{array}$ & $\begin{array}{c}\text { № Concejales } \\
\text { electos }\end{array}$ \\
\hline PC & 87 & \\
\hline IU & 510 & \\
\hline PSPC & 2.307 & 2 \\
\hline PP & 8.867 & 9 \\
\hline PFC & 5.778 & 6 \\
\hline CEU & 4.171 & 4 \\
\hline $\mathrm{CP}$ & 407 & \\
\hline PSOE & 3.370 & 3 \\
\hline PDSC & 1.449 & 1 \\
\hline CEM & 1.111 & \\
\hline
\end{tabular}




\section{MELILLA}

№ Electores:

42.820

№ Votantes:

26.432

№ Votos de candidatura: $\quad 26.057$

№ Votos en blanco:

265

№ Votos válidos:

26.322

№ Votos nulos:

110

\begin{tabular}{lrc}
\hline \multicolumn{1}{c}{ Candidaturas } & $\begin{array}{c}\text { Votos } \\
\text { obtenidos }\end{array}$ & $\begin{array}{c}\text { No Concejales } \\
\text { electos }\end{array}$ \\
\hline Unión del Pueblo Melillense & 2.605 & 2 \\
IU & 715 & \\
Partido Nacionalista de Melilla & 1.008 & \\
Coalición por Melilla & 4.072 & 4 \\
PP & 12.425 & 14 \\
PSOE & 5.232 & 5 \\
\hline
\end{tabular}

